NBER WORKING PAPER SERIES

HEALTH CAPACITY TO WORK AT OLDER AGES IN FRANCE

\author{
Didier Blanchet \\ Eve Caroli \\ Corinne Prost \\ Muriel Roger \\ Working Paper 22024 \\ http://www.nber.org/papers/w22024 \\ NATIONAL BUREAU OF ECONOMIC RESEARCH \\ 1050 Massachusetts Avenue \\ Cambridge, MA 02138 \\ February 2016
}

The views expressed herein are those of the authors and do not necessarily reflect the views of the National Bureau of Economic Research.

NBER working papers are circulated for discussion and comment purposes. They have not been peerreviewed or been subject to the review by the NBER Board of Directors that accompanies official NBER publications.

(C) 2016 by Didier Blanchet, Eve Caroli, Corinne Prost, and Muriel Roger. All rights reserved. Short sections of text, not to exceed two paragraphs, may be quoted without explicit permission provided that full credit, including $(\mathcal{O}$ notice, is given to the source. 
Health Capacity to Work at Older Ages in France

Didier Blanchet, Eve Caroli, Corinne Prost, and Muriel Roger

NBER Working Paper No. 22024

February 2016

JEL No. I10,J14,J21,J26

\begin{abstract}
France stands out as a country with a low labor force attachment of older workers. A reversal in the trend of French labor participation rates over 50 is under way, partly due to the pension reforms that took place since 1993. The French ageing process is driven by large gains in life expectancy and Pension reforms allocate part of these gains to work rather than to retirement. The implicit assumptions guiding the reforms have been that additional years of life are years with a health status that can be considered reasonably compatible with work. If this is not the case, the idea of sharing these additional years of life between work and retirement is questionable.
\end{abstract}

Considering mortality and health status, we question the fact that the reforms may have gone too far in increasing the retirement age. To tackle these issues, we rely on two different methodological approaches developed in the economic literature: one based on the gap in employment rates across time for given mortality rates; the other using the work/health relationship measured at certain ages to predict the health-related work capacity of older age groups at the same period of time. Both methods aim at providing measures of additional work capacity. This capacity may be defined as a measure of the distance between current retirement ages and what we call the "health barrier", i.e. the age at which health prevents people from working longer.

Both methods predict high average levels of additional work capacity. However, the picture becomes somewhat different when disaggregating the results by social groups or education. Our results emphasize the idea that policies aiming at activating any estimated additional work capacity should take into account, when possible, the heterogeneity of health conditions in the population. Moreover, additional work capacity cannot be a general indicator of how much seniors should work. The methods used here indeed leave aside many factors that determine the employment rate of older workers.

Didier Blanchet

INSEE- CREST

15 Blvd. Gabriel Péri BP 100

92244 Malakoff Cedex FRANCE

didier.blanchet@insee.fr

Eve Caroli

PSL, University Paris Dauphine, LEDa-LEGOS,

Paris School of Economics and IZA

Place du Maréchal de Lattre de Tassigny

75775 Paris Cedex 16 France

eve.caroli@dauphine.fr
Corinne Prost

INSEE- CREST

15 Blvd. Gabriel Péri BP 100

92244 Malakoff Cedex FRANCE

prost@ensae.fr

Muriel Roger

Paris School of Economics - INRA

48 Bd JOURDAN

75014 PARIS

France

mroger01@pse.ens.fr 


\title{
Health capacity to work at older ages in France
}

\author{
Didier Blanchet \\ Eve Caroli Corinne Prost \\ Muriel Roger
}

June 2015

\section{Introduction}

Among comparable countries, France traditionally stands out as one of those where the labor force attachment of older workers is the lowest. This has been especially the case from the mid-80s to the beginning of the 2000s (Figure 1). The employment rate for the 60-64 age group was only $10 \%$ in 2000, 25 points below the OECD average, following a period of continuous decline that had started early in the 1970s. The decrease has been more limited for the 55-59 age group but nonetheless substantial. It has been concomitant with the shift of the legal retirement age from 65 to 60 which took place during the first half of the 1980s and favored a phase of rapid expansion of preretirement policies targeted to this 55-59 age group. This expansion was rapidly interrupted, but employment rates for male workers aged 55-59 then remained as low as about $60 \%$ throughout the 1990s and the first half of the 2000s, more than 10 points below the equivalent OECD average over the period.

Yet, the long run view provided by Figure 1 also shows that low employment rates for the 55 and above cannot be seen as a constant and irreversible feature of the French labor market. First of all because preexisting historical levels were not low at all: the decrease that occurred until the 1990s started from initial values that, in 1975, were close to OECD standards. And second because employment rates have entered a new ascending phase over the last fifteen years. Concerning the 55-59 age group, the average employment rate for both genders has already reincreased from 50\% in 2000 to 66\% in 2013, above its 1975 value and in line with the OECD average. Part of this trend stems from increased labor force attachment by women of all ages, rather than from a tendency to work more at older ages. But the movement is also very significant for men, whose employment rate has increased by 10 points since 2008, despite the adverse economic conditions. Concerning the 60-64 age group, the change is more progressive but not less substantial: employment rates have regained 15 percentage points, for both men and women. This is still much below the OECD average, but the convergence is real since the trend in France is steeper than for the OECD as a whole. 
Figure 1 - Employment rates since 1975, 55-59 and 60-64 age groups

a : $55-59$

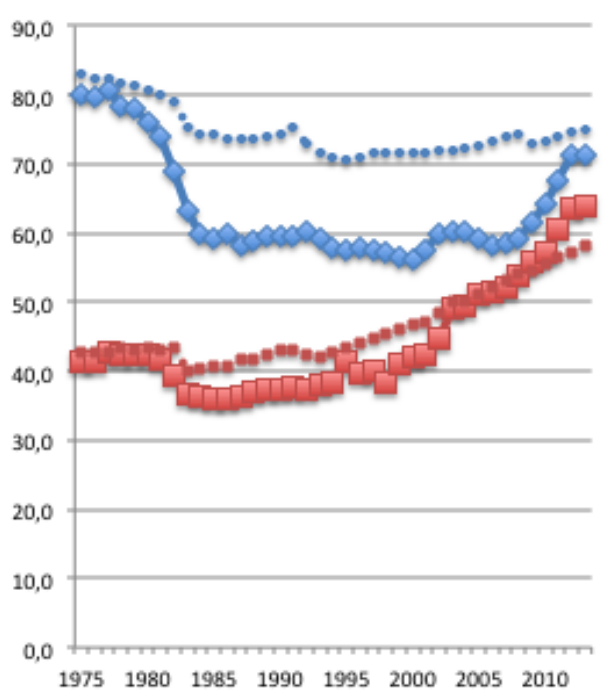

b : $60-64$

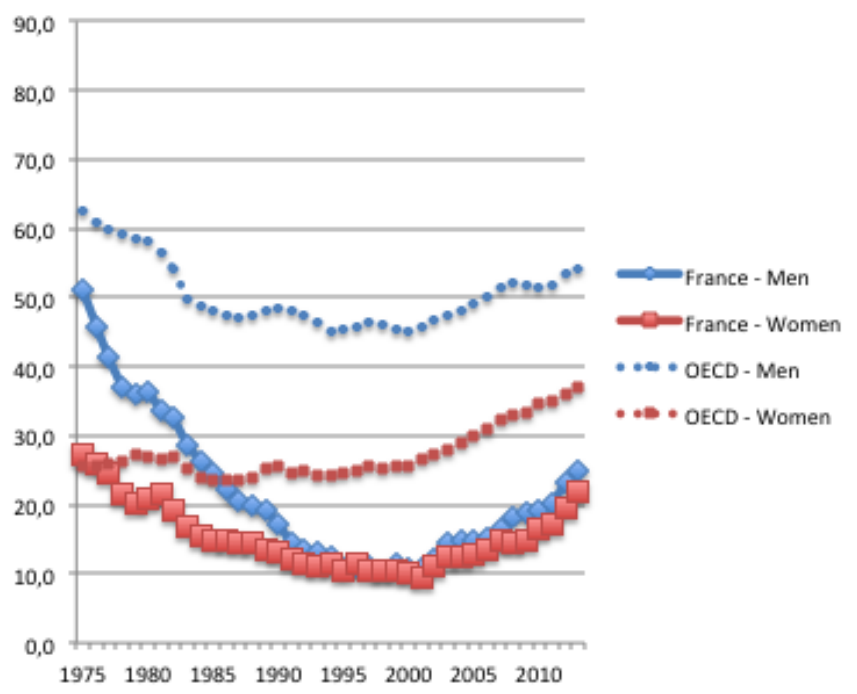

Source: INSEE and OECD, Labour Force Surveys.

A reversal is therefore undoubtedly under way, partly due to tighter preretirement policies, and partly to the pension reforms that took place since 1993. According to the latest pension projections published by the Conseil d'Orientation des Retraites (Pensions Advisory Committee), if things go on as currently expected, this upward trend in employment rates should persist over the next decades, leading by 2040 to levels close to the ones that were observed in the early 70 s.

The fact that most of the French ageing process is driven by large gains in life expectancy has been particularly helpful in preparing this reversal: allocating part of these gains to work rather than to retirement has been presented by policy makers as a natural and relatively acceptable way to contain the progression of pension expenditures.

In such a context, arguing both in favor of the possibility and the need to increase retirement ages and older workers' employment appears to be much less necessary than it used to. Yet some questions and doubts remain. An implicit hypothesis of all past reforms has been that additional years of life are years spent in good health, or at least with a health status that can be considered reasonably compatible with work. If this is not the case, the idea of sharing these additional years of life between work and retirement becomes much less self-evident. 
There is even the view that pension reforms themselves could widen the gap between global and healthy life expectancies, if they induce people to work at ages where work constraints strongly deteriorate health. In other words, a question that can be asked is whether reforms have not gone "too far" in activating the retirement age variable. Are we approaching a "health barrier" to longer working lives that would have been too rapidly ignored by past reforms? This question can be asked "on average" but also, and probably more interestingly, separately by occupations or socio-professional groups, thus questioning the adequacy of excessively uniform policies that pay too little attention to differential exposures to morbidity or mortality risks.

To tackle these issues, we rely on two different methodological approaches currently developed in the economic literature. Both methods and their variants aim at providing measures of additional work capacity. This capacity may be defined as a measure of the distance between current retirement ages and what we call the "health barrier", i.e. the age at which health prevents people from working longer.

We first implement the method developed by Milligan and Wise (2012), denoted thereafter MW, using mortality as a proxy of health. These authors compute a measure of additional work capacity for older workers (aged 55-69), based on the gap in employment rates across time for given mortality rates. With the increase in longevity over time, the same mortality rate corresponds to different ages at different years. We extend the standard MW method, on the one hand, taking into account intra-generational mortality differentials and, on the other hand, using direct indicators of health status rather than the mortality proxy.

Second, as the MW method remains highly dependent on the reference period, we complete the study considering an alternative method, developed by Cutler, Meara and Richards-Shubik (2013), denoted thereafter CMR, that does not require any comparison over time. The approach becomes synchronic, using the work/health relationship measured at certain ages to predict the health-related work capacity of older age groups at the same period of time.

Both methods and their variants aim at providing measures of additional work capacity, i.e. measures of the existing distance between current retirement ages and our suggested concept of "health barrier". However, they do not tell us by how much retirement ages should be increased. Individual and/or social choices concerning retirement ages need to consider many other parameters, both on the supply and the demand side of the labor market. 
What is at stake here is only one very specific aspect of the global optimization problem that would consider all these variables at the same time: it entails no message about how far policies should go in "exploiting" the employment reserve measured by additional work capacity. Evaluating where the health barrier is standing is one thing, making recommendations about how close to this barrier one should come is another thing, that is clearly out of the scope of the present paper.

Section 1 will present the application of the MW method in its original form, using long-run series of mortality rates as proxies of health status, with an extension taking into account intra-generational mortality differentials. This extension is made possible for France, thanks to a long tradition of production of life tables for major socio-economic groups. Section 2 will explore the possibility to adapt the MW method using direct indicators of health status rather than the mortality proxy, relying on the Enquête Santé et Protection Sociale (ESPS) conducted by IRDES from 1992 to 2010. The CMR method will be discussed at last in Section 3. Section 4 will conclude with a short discussion of the limitations to increasing retirement ages that are not covered in the present paper.

\section{Employment rates and mortality: the Milligan-Wise approach}

The Milligan-Wise methodology consists in using mortality as a proxy of health and then compute a measure of additional work capacity for older workers (aged 55-69), based on the gap in employment rates across time for given mortality rates. Data on mortality come from the French Statistical Institute, INSEE. We match them with employment rates by age computed using the French Labor Force Surveys (Enquête Emploi) over 1977-2012.

The main advantage of this approach is that the results are easily comparable across countries since mortality and employment are defined in a consistent way across national data. In contrast, it cannot be extended to women in a meaningful way over the period we consider because of the large shift in female labor force participation across cohorts. So, the focus of this section will be on men only.

\section{Employment vs mortality over time}

The starting point of the MW methodology is the observation that in all advanced countries, both mortality and employment rates have substantially declined over the past forty years. France is no exception to these trends with male death rates at 55, 60 and 69 going down from $1.13 \%$ (resp. $1.67 \%$ and $3.45 \%$ ) in 1977 to $0.62 \%$ (resp. $0.86 \%$ and $1.67 \%$ ) in 
2012. Over the same period, employment rates of men have gone down from $90.1 \%$ at age 55 (resp. $75.1 \%$ at 60 and $15.4 \%$ at 69 ) in 1977 to $82.9 \%$ at age 55 (resp. $57.3 \%$ at 60 and $4.3 \%$ at 69) in 2012.

A more telling way of presenting these changes is provided on Figure 2. We graph employment rates as a function of death rates for three different years: 1977, 1995 and 2012. For given death rates, employment has strongly decreased over time. The death rate of individuals aged 59 in 1977 (i.e. 0.0169) was reached at about 68 years old in 2012, while the corresponding employment rates are hugely different: $75.1 \%$ for the 59 year olds in 1977 as compared to only $4.3 \%$ for the 68 year olds in 2012 . The changes that have taken place have generated an inward shift in the mortality-employment schedule.

This suggests that if bad health conditions - as captured by mortality - were the main obstacle to employment, older workers - aged 55 and above - could be working much more than they actually do.

Figure 2 - Employment vs Mortality - Men

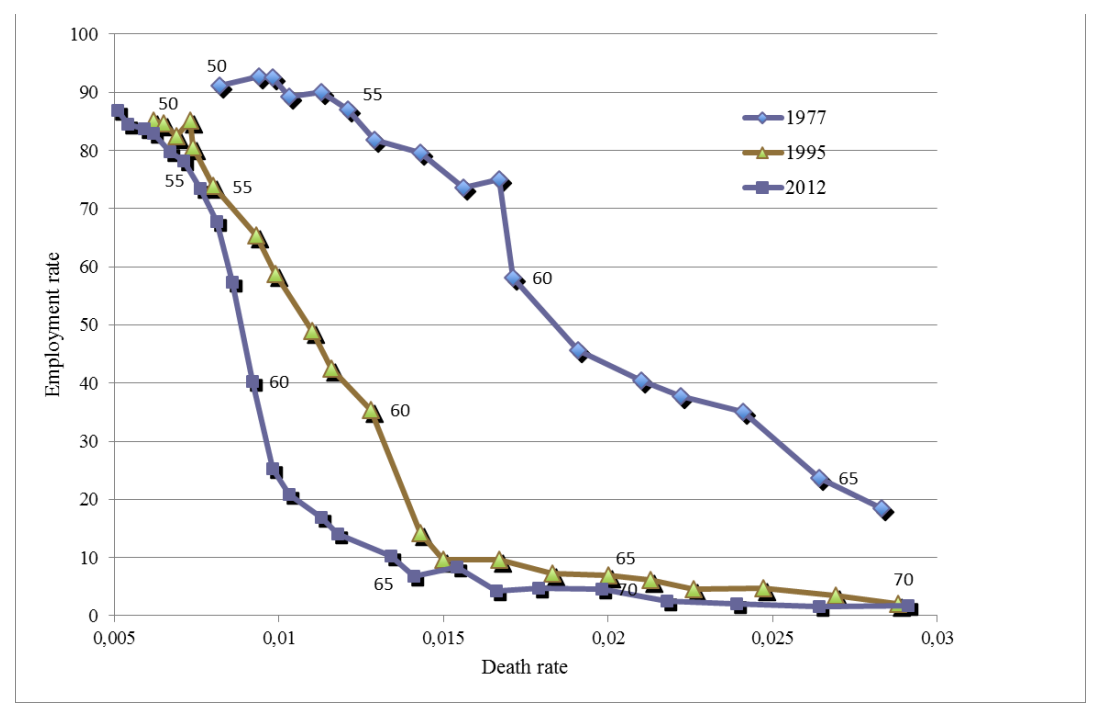

\section{Measuring mortality-based work capacity}

To get a precise measure of this additional work capacity, we proceed in the following way: for each level of death rate, we consider what the employment rate would be at any year $t$ if the relationship between employment and mortality were the same at $t$ as in a reference year - taken here to be 1977 . We cumulate this calculation over age 55-69. This gives us the number of additional years French men could have worked between 55 and 69 if the 
employment-mortality relationship had not changed since 1977 - see Figure 3. The additional number of years of work computed in this way is referred to as "additional work capacity".

Figure 3 - Mortality-based additional work capacity Men 55 to 69, 1978 to 2012, using 1977 as reference year

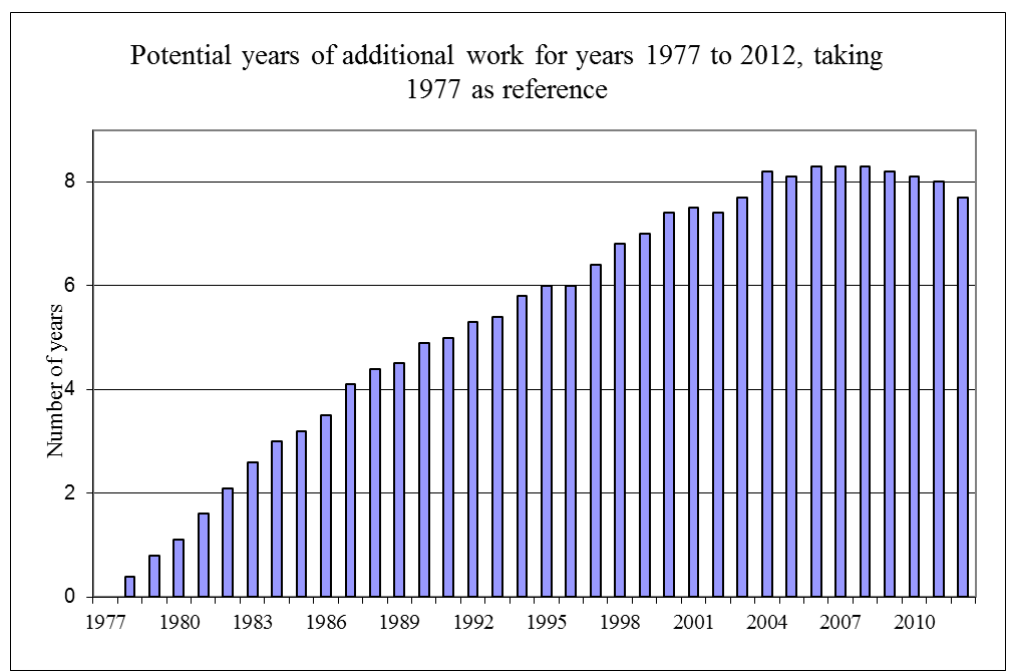

According to this calculation, the additional work capacity strongly increased from 0.4 years in 1978 to a peak of 8.3 years in the mid-2000s. The trend started to revert in 2009 and the additional work capacity was back to 7.7 years in 2012 .

Given that we compute the additional work capacity on the basis of the gap in employment rates between year $t$ and a reference year, it heavily depends, by construction, on the reference year that is chosen: the higher the employment rate in the reference year, the higher the additional work capacity we obtain. Since employment rates have steadily decreased in France until 2010, the additional work capacity mechanically increases with the time distance to the reference year. For year 2012, for example, it ranges from 7.3 years if the reference year is 1977 to -0.2 years if the reference year is 2010 - see Figure 4. 


\section{Figure 4 - Additional work capacity for men in 2012 using 1977 to 2011 as reference years}

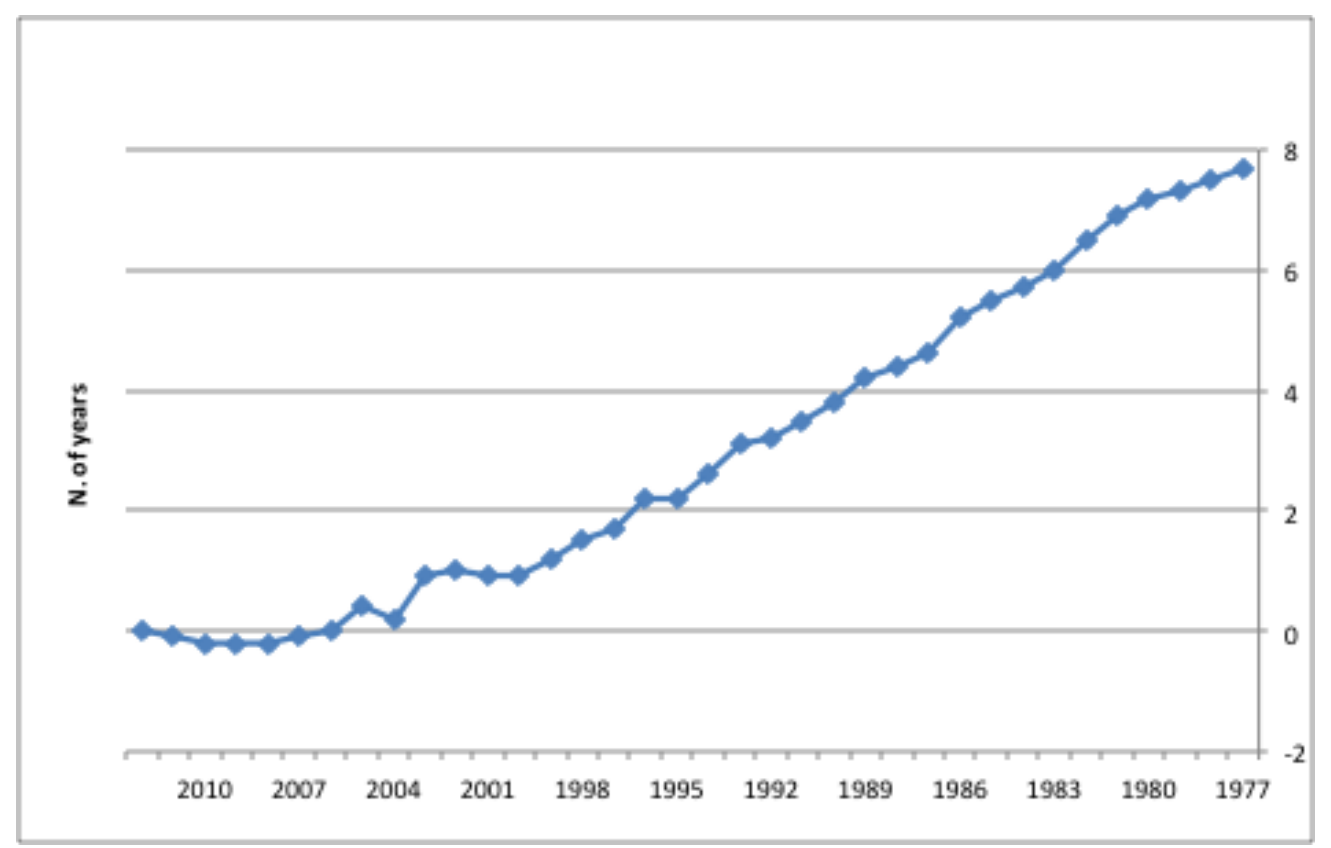

The limitations of the mortality-based Milligan-Wise approach

The MW estimates deliver extreme upper bounds for potential increases in labor force participation rates, i.e. evaluations of ages beyond which health limitations definitely preclude further prolongations of working lives, according to some conventional historical standards corresponding to the reference year. To interpret the results, we must bear in mind some limits of the method. The first one is that (a) it is based on a proxy of health status whose relevance is not warranted: if past declines in mortality rates have not been accompanied by equivalent declines in morbidity, the MW method will overestimate the margin that is available for increasing employment rates of older workers. A second limit (b) is the intrinsically relative character of the results: as illustrated above, they are completely dependent on the reference period used for assessing the current level of additional employment capacity. A third limit (c) is the aggregate nature of the method: it is based on average values of age-specific mortality rates, thus ignoring the strong heterogeneity of mortality risks in the population.

Limit (a) will be addressed in the next section when we examine whether the MW method can be made more to the point by using true measures of health, rather than the mortality proxy. The last section of this chapter will try to overcome limit (b): the Cutler et al. (2013) method that will be used will avoid comparisons over time, replacing them by 
comparisons at time $t$ across age groups. These two sections will also address limit (c), by looking at differentials in health status as observed by education level or other descriptors of socio-economic status. But a first look at the heterogeneity issue can already be provided here, without exiting the strict MW framework, thanks to the availability, for France, of mortality data by social group.

Heterogeneity in mortality-based work capacity: managers and professionals vs bluecollars

Disaggregating life tables according to socio-economic status has a relatively long tradition in France since first systematic attempts go back to the 60s and 70s (Calot and Febvay, 1965; Desplanques, 1976). The approach combines civil registration data with information collected at successive censuses: although civil registration data provide exact age at death, they do not contain any reliable information on social status, which can be retrieved from individual census bulletins. The first studies of this kind used one-shot ad hoc confrontations of both pieces of information. Nowadays, the Echantillon Démographique Permanent (Permanent Demographic Sample), maintained at the French Statistical Institute INSEE, systematically matches both kinds of information for a $1 \%$ representative sample of the French population. Thanks to this panel, life tables disaggregated by social group are available off-the-shelf for the following aggregate time periods 1976-1984, 1983-1991, 19911998 and 2000-2008 (Blanpain and Chardon, 2011).

In these data, social stratification is described on the basis of the 7-digit French socioeconomic classification. We shall focus here on managers/professionals and blue collars. In 1976-1984, life expectancies at age 35 were 41.7 years for the former group and 35.7 for the latter, i.e. a six-year gap. In 2000-2008, the corresponding figures were 47.2 and 40.9 , i.e. a 6.3 year gap. At age 55, values for 1976-1984 were 23.3 and 19.2, i.e. a 4.1 year gap. For 2000-2008, they were respectively 28.4 and 23.5, i.e. a 4.9 year gap. Absolute differences are, of course, smaller at 55 than at 35 but this is only due to the fact that life expectancy decreases with age. Reevaluated in relative terms, in 2000-2008, the gap was $14 \%$ at age 35 and close to $19 \%$ at age 55 .

How can such a feature be incorporated into the MW framework? The procedure we propose here fully respects the general spirit of the method and does not make use of socioeconomic mortality differentials for remote time periods: only data for the most recent years are sufficient. We keep the hypothesis that average mortality-employment relationships of all 
past periods can be used as benchmarks, and apply these successive benchmarks to mortality rates currently observed in the two social groups we consider. The counterfactual employment rates that are produced on the basis of these group-specific mortality rates are then compared to the true employment rates observed for the same groups. The period of interest is the median year of the latest time period for which differential mortality is available, i.e. year 2004. More precisely, we use mortality rates for 2000-2008 as proxies of mortality rates by social group in 2004 and, concerning employment rates, we average them over a three-year period centered around 2004, i.e. 2003-2005.

Another option would be to compute MW additional work capacities for each of our social groups using group-specific employment/mortality relationships. Yet this would only give a measure of how much blue collars (resp. managers/professionals) may work considering their own mortality and employment rates in the reference year, with little or no insight into the differential between them. For instance, in case of perfectly parallel changes in mortality and employment for the two groups, the result would be identical levels of additional work capacities for both, whatever the level of cross-sectional inequality between them. Put differently, this would consider that the differential gap in the reference year is also a reference and can be considered as "normal". With our methodology, we consider that the reference is the link between employment and mortality in the average population, and this sheds a better light on the situation of disadvantaged social groups.

The resulting additional work capacities of managers/professionals and blue-collar workers for year 2004 are shown on Figure 5 using 1977 to 2004 as successive reference years. This figure also replicates the previous computation for the general population, with 2004 rather than 2012 as the new year of interest. Understanding the results in figure 5 also requires looking at figure 6 , which provides the apparent mortality-employment relationship for managers/professionals and blue collars in 2004, as well as the same relationship for the general population both in 2004 and 1977. 
Figure 5 - Mortality-based additional work capacities by social group in 2004 Men 55 to 69, using 1977 to 2004 as reference years.

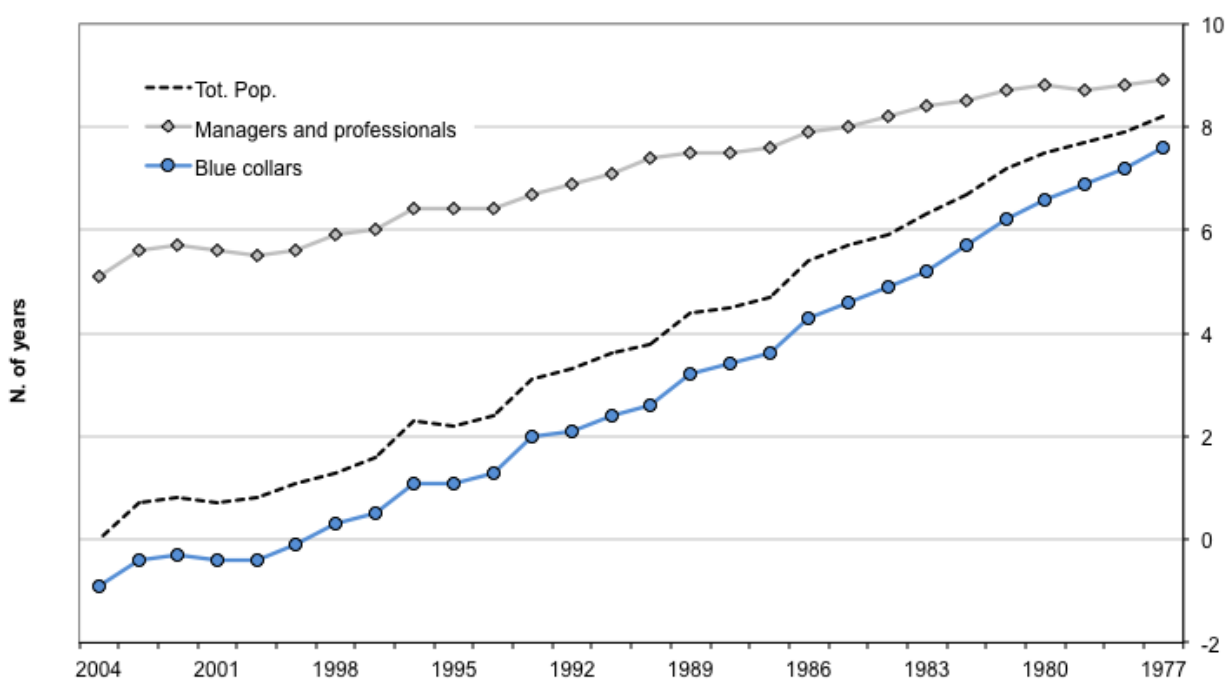

Figure 6 - Employment vs Mortality - Men Total population, managers/professionals and blue collars

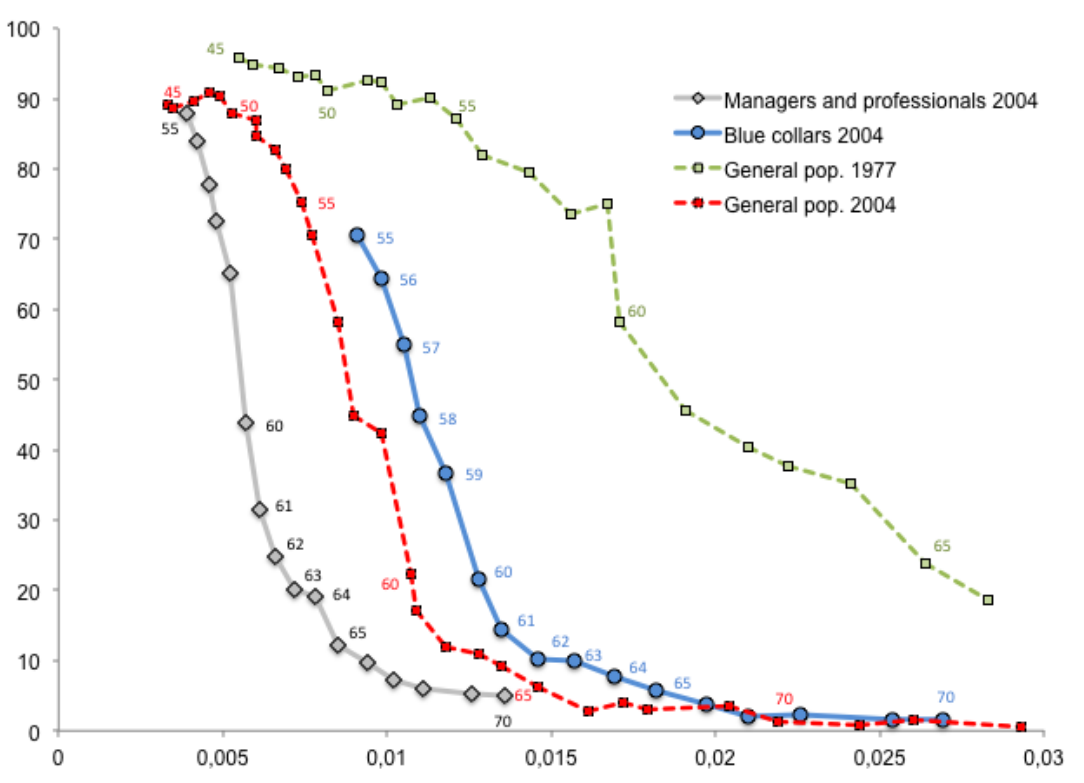

Results using 2004 as the reference year are instructive in that they reveal the current state of inequalities in terms of employment-mortality relationship. If the 2004 relationship is taken as a reference, the average additional work capacity is zero by construction, but it is as high as +5.1 years for managers and professionals whereas it is negative for blue collars, 
equal to -0.9 years. Managers and professionals work much less than they could do according to the MW a priori -, while blue-collar workers work slightly longer than what they should be asked to. Another way to look at these figures is to note that blue-collar workers aged 55 had a rate of employment of 70\% in 2003-2005, while managers and professionals the same age had a rate of employment of $87.9 \%$. Over this time period, the former had a mortality rate of .0091 while the latter reached this mortality rate at only 65 or 66 years old, i.e. ages at which their employment rates were around $10 \%$. This means that, if we consider 2004 managers and professionals as the reference group, blue-collar workers suffer from a 60 percentage-point «excess» work duration. Such considerations raise the question of differentiating the efforts in additional years of work that could be demanded to the different groups, in view of their current mortality levels.

In principle, the same message should remain valid when pushing the reference year backward in the past, with parallel increases of the indicators of additional employment capacity for managers/professionals and blue collars. Figure 5 suggests that this is not the case since the additional work capacities of both groups seem to be much closer to each other when 1977 is taken as the reference year -7.6 years and 8.9 years, respectively. However, this paradoxical result is due to an artifact generated by the way the MW method is implemented, i.e. imposing an arbitrary upper limit at 69 for the age bracket over which counterfactual employment rates are simulated. The consequence of this arbitrary limit can be understood looking at figure 6: as the method is applied here, the difference between the upper 1977 schedule and the bottom schedule for managers and professionals in 2004 is integrated only until about half way through the figure. Abandoning such a convention, the MW approach would reveal a considerable amount of additional work capacity for managers and professionals on the right-hand side of the graph. The impact of removing the 69 year-old age constraint is expected to be much more modest for blue-collar workers since, when integrating for them within this limit, we go up to values of mortality rates for which employment rates were already low - typically below 20\% - in 1977 . This is confirmed by figure 7, equivalent to figure 5 after removing the 69 year-old limit for computing counterfactual employment rates: an almost complete parallelism is restored between the profiles of additional work capacity for managers/professionals, blue-collar workers and the average population. 
Figure 7 - Mortality-based additional work capacities by social group in 2004

Men 55 +, using 1977 to 2004 as reference years.

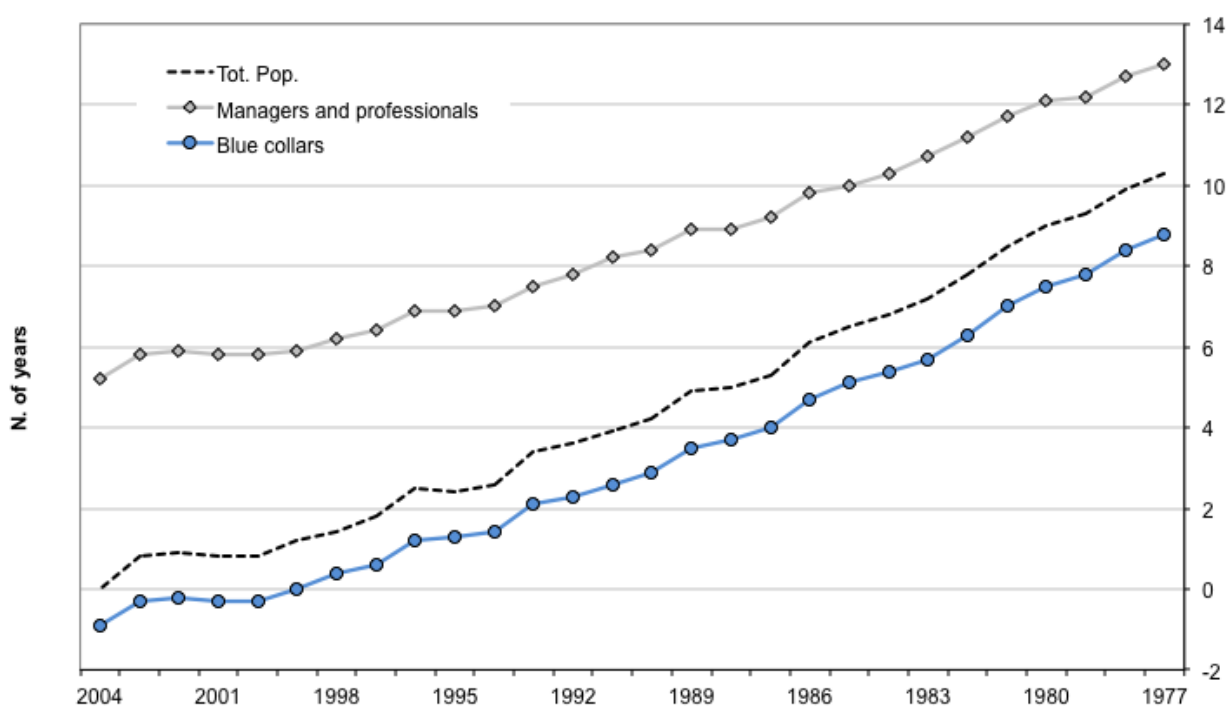

Of course, this generates levels of additional work capacity for managers and professionals that look highly implausible - up to 13 years with 1977 as the reference year. It incidentally highlights a limit of the MW method. This generates estimates of additional work capacities that remain within a plausible range only thanks to the choice of an arbitrary upper age limit until which the methodology is considered valid.

Mortality-based work capacity: what have we learnt?

The MW approach based on mortality yields very high estimates of additional work capacity. This does not mean that all this capacity should actually be used. It only suggests that, on average, health does not appear to be a major limiting factor to the increase in labour force participation of older workers. However, one has to go beyond averages and take into account the very uneven levels of mortality rates across social groups. This point is clearly supported by the analysis carried out using the data on mortality by social status available for France. Moreover, as already underlined, mortality remains a very crude proxy of health. The next sections try to overcome this drawback. 
3. Employment rates and self-assessed health implementing the Milligan-Wise approach

This section addresses the concern that mortality could be a poor proxy of health by considering a more direct measure of it, i.e. self-assessed health (SAH).

The data on SAH for France are provided by the ESPS (Enquête sur la Santé et la Protection Sociale) Survey. This survey was conducted yearly from 1992 to 1997 on a rather small sample of individuals (about 1,000 per year) and every other year from 1998 to 2010 on a larger sample (about 2,000 respondents per year). SAH is measured consistently since 1992 on a $0-10$ scale and we define poor $\mathrm{SAH}$ as a dummy variable equal to 1 if reported $\mathrm{SAH}$ scores below 8 (which corresponds to the first quartile of the distribution both for men and women in 1992) and 0 otherwise.

\section{Trends in SAH over time}

Figure 8 (resp. 9) shows the relationship between poor SAH and age, on the one hand, and mortality and age on the other hand for men (resp. women). Both figures provide evidence of an age gradient in SAH and mortality, although the relationship is less smooth for SAH because of small sample size. The proportion of men reporting poor SAH in 2010 is almost three times as large at age 75 as at $50-70 \%$ as compared to $25 \%$. Age trends are less pronounced for women since the proportion reporting poor SAH is equivalent to men at age $75-70 \%$ - but is much higher at age $50-40 \%$. This is consistent with the difference we observe across gender in the age gradient in mortality, the latter being larger for men than for women.

Yet, contrary to what we might expect - and to what is observed for mortality for men above 55 and for women above 70 -, we do not see any steady improvement in SAH over time whatever the age group we consider - see Figures 10 and 11 below. After a decline in the proportion of men and women reporting poor SAH in the first half of the 1990s, the trends revert at the beginning of the 2000s and SAH appears to deteriorate for both men and women, at least until the very last years of the decade. 
Figure 8 - Poor SAH and Mortality - Men, by age 1992-2010

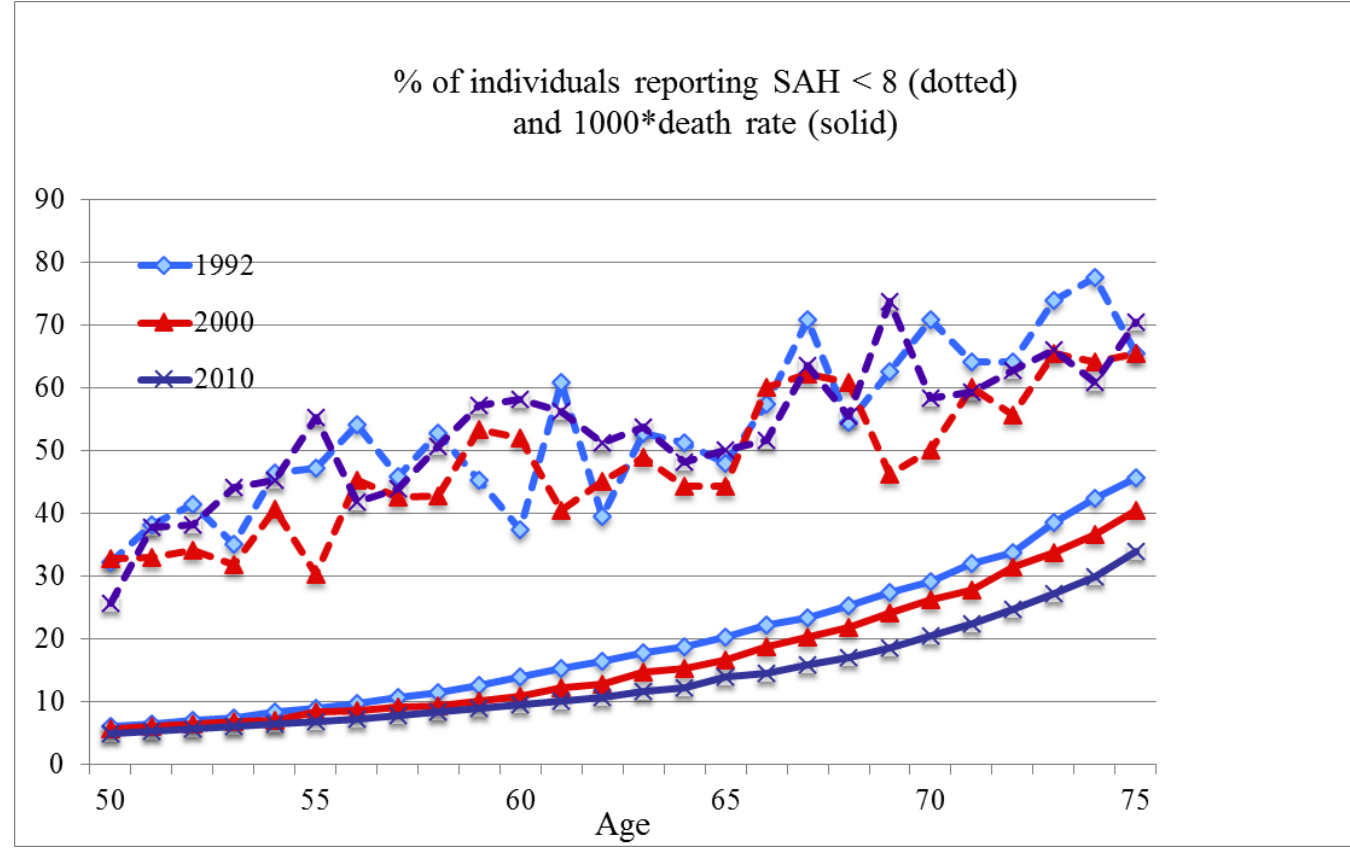

Figure 9 - Poor SAH and Mortality - Women, by age 1992-2010

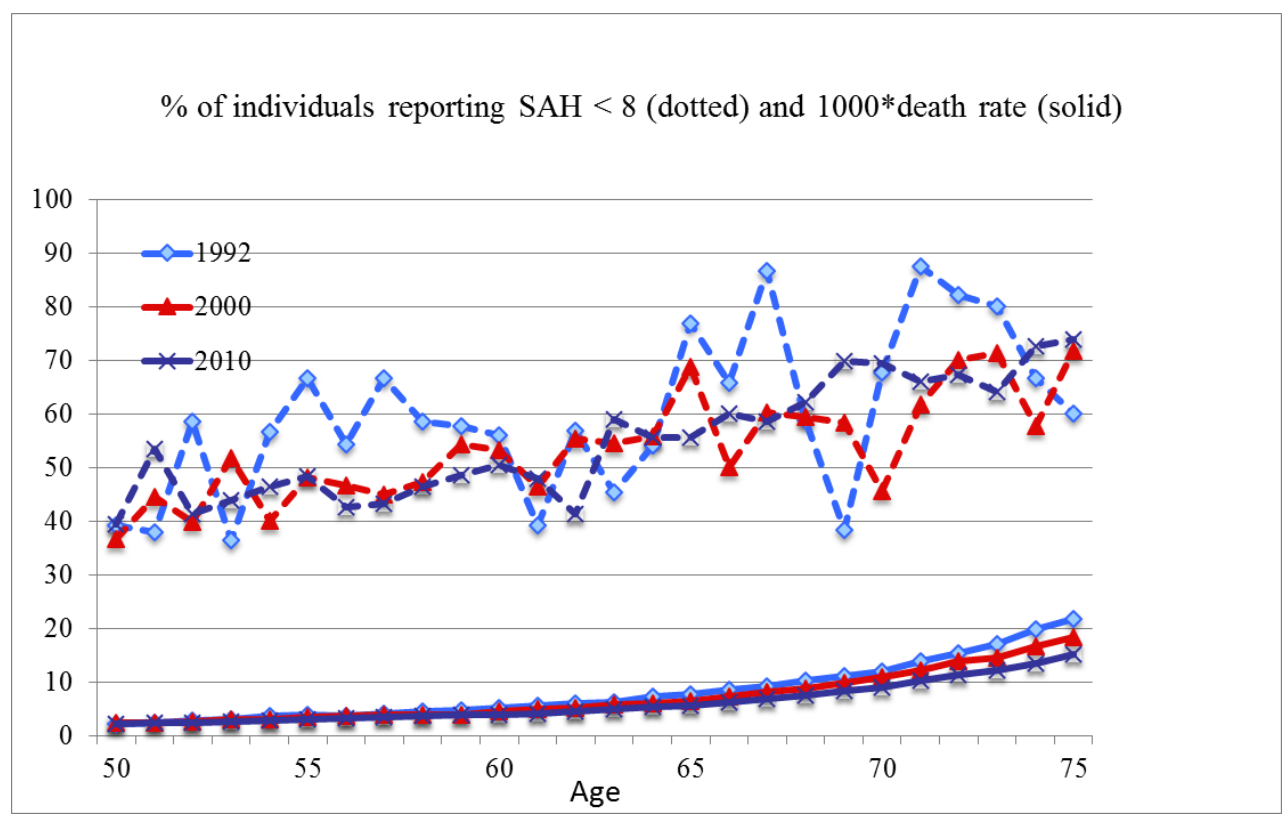


Figure 10 - Poor SAH by age group across time - Men 1992-2010

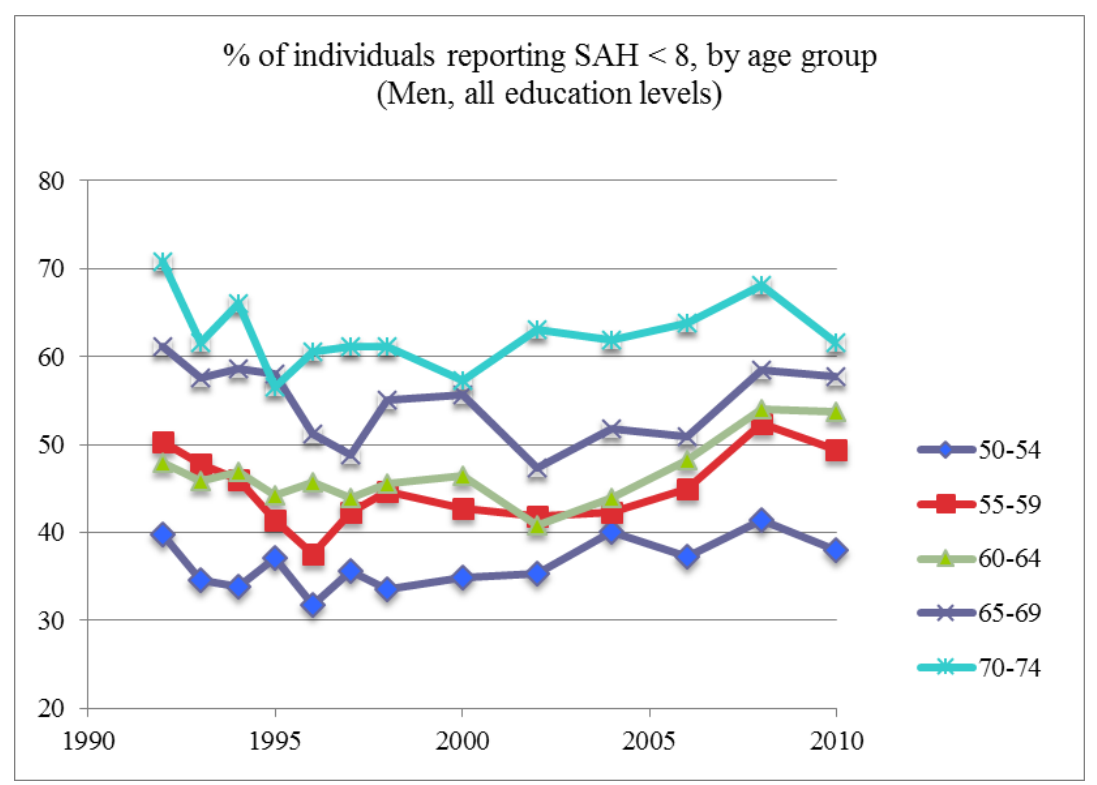

Figure 11 - Poor SAH by age group across time - Women 1992-2010

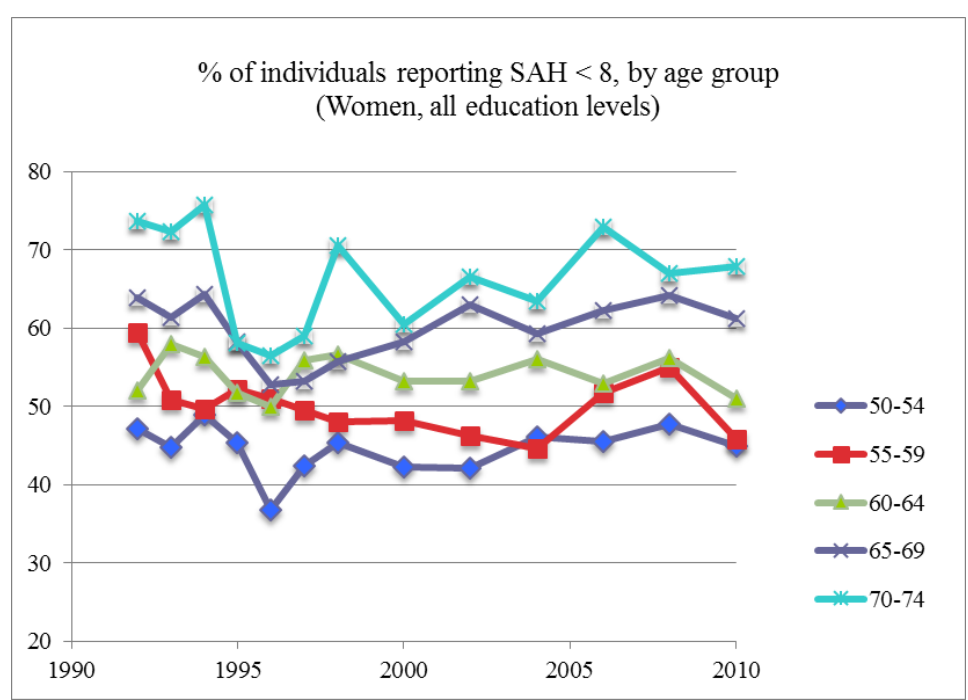

The lack of clear improvement in self-assessed health over time in our data raises the issue of potential declaration biases. There is evidence in the literature that, when asked about their health, individuals in various subgroups of the population use different threshold levels to assess it, although having the same "true" health level. This gives rise to reporting heterogeneity which varies according to the type of health outcome that is considered (Tubeuf et al, 2008). As regards SAH, low-income and low-education individuals tend to over-report it 
(Bago d'Uva et al, 2011; Etilé and Milcent, 2006; Johnston et al, 2009), while women tend to under-report it as compared to men (Bago d'Uva et al, 2008). As regards age, Lindeboom and van Doorslaer (2004) find that older adults are more inclined than younger ones to report good health for a given health status. If this happens to be the case in our data, the agegradient evidenced in Figures 8 and 9 must be considered as a lower bound since it is negatively affected by this declaration bias. However, in order for declaration biases to account for the lack of improvement in SAH over time, it would have to be the case that, within age groups, individuals tend to under-report their health status to a larger extent than they used to in the past. This may be the case if, as health systems become more efficient, individuals raise their health expectations. However, to our knowledge, there is no evidence of such trend in the literature.

A competing explanation of why time trends in poor SAH do not look more downward sloping may be that they are quite heterogeneous across social groups, with health getting better for some groups while it may have worsened for others.

\section{Trends in SAH by education}

One of the most obvious social classification to look at is the one based on education. This can be done using the ESPS Survey which contains information on educational levels grouped into 5 categories until 2006 and into 8 and 9 groups in 2008 and 2010, respectively.

In order to compute meaningful changes in SAH by education level over time, we need to take into account the upward shift that has taken place in the educational composition of the population. One of the consequences of this shift is that low-educated workers are more selected in recent years than they were in the past. To account for this change, we first compute the distribution of years of education by cohort and gender - see Figures 12 and 13 for men and women, respectively; the distribution for the whole population is shown on Appendix Figure AA0. 
Figure 12 - Distribution of years of education completed by cohort - Men (year each cohort attained age 50)

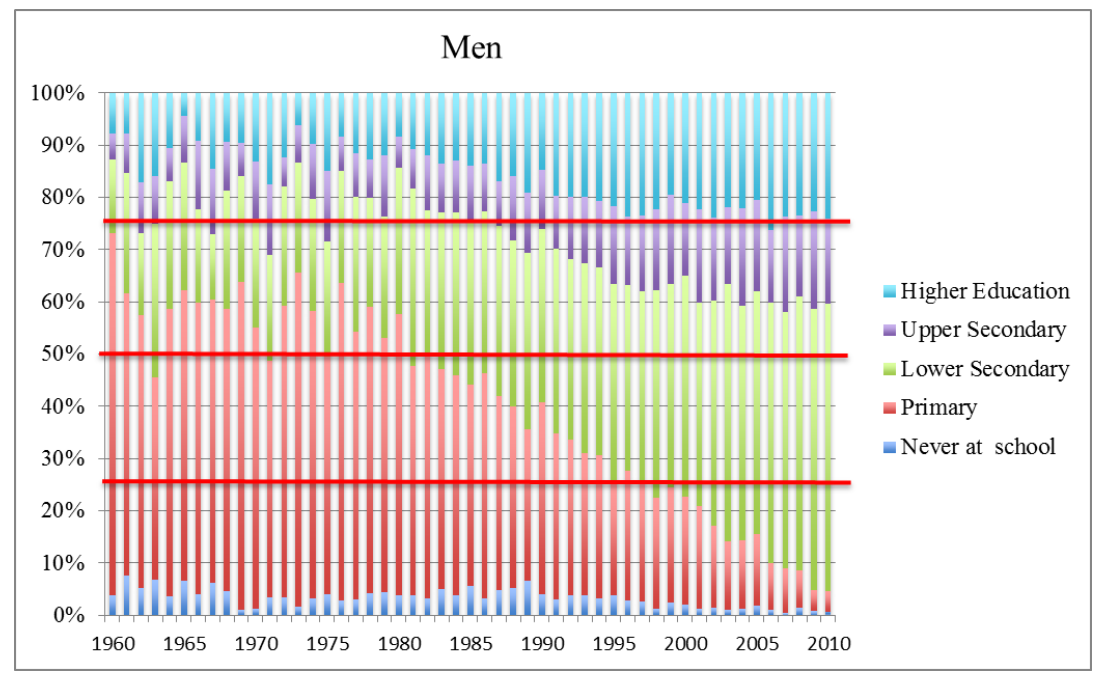

Figure 13 - Distribution of years of education completed by cohort - Women (year each cohort attained age 50)

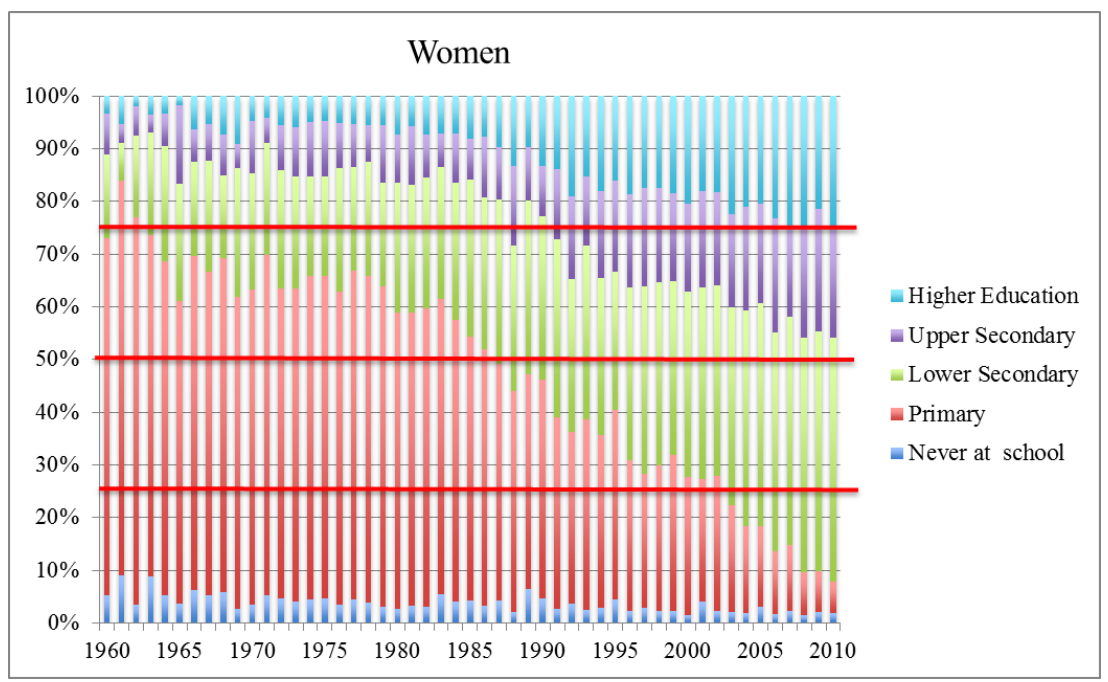

As can be seen on Figure 12, the proportion of men having completed at least some higher education increased substantially between the cohorts who reached 50 in 1960 and in 2010. The same goes for the proportion with upper secondary education and for those with lower secondary education. In contrast, the share of men with only primary education has sharply declined. Those who never attended school represent a small share of the cohort who reached 50 in 2010 but it was already low for the 1960 cohort. Similar trends are observed for 
women - see Figure 13 - although the proportion that attains higher education in the 2010 cohort remains slightly lower than for men.

As a second step, we sort individuals by education in each age*year cell with random ordering of individuals within each level and define four education quartiles. Over the 40 years considered here, the educational level of the median male and female increased from primary to lower secondary education. The first quartile did the same while the third one moved from lower secondary education to upper secondary education.

The proportion of individuals reporting poor SAH is then computed for each single age over 50-75 in each education quartile and eventually aggregated over two time periods: 1992-1998 and 2000-2010.

Figure 14 - Poor SAH by education quartile - Men 1992-2010
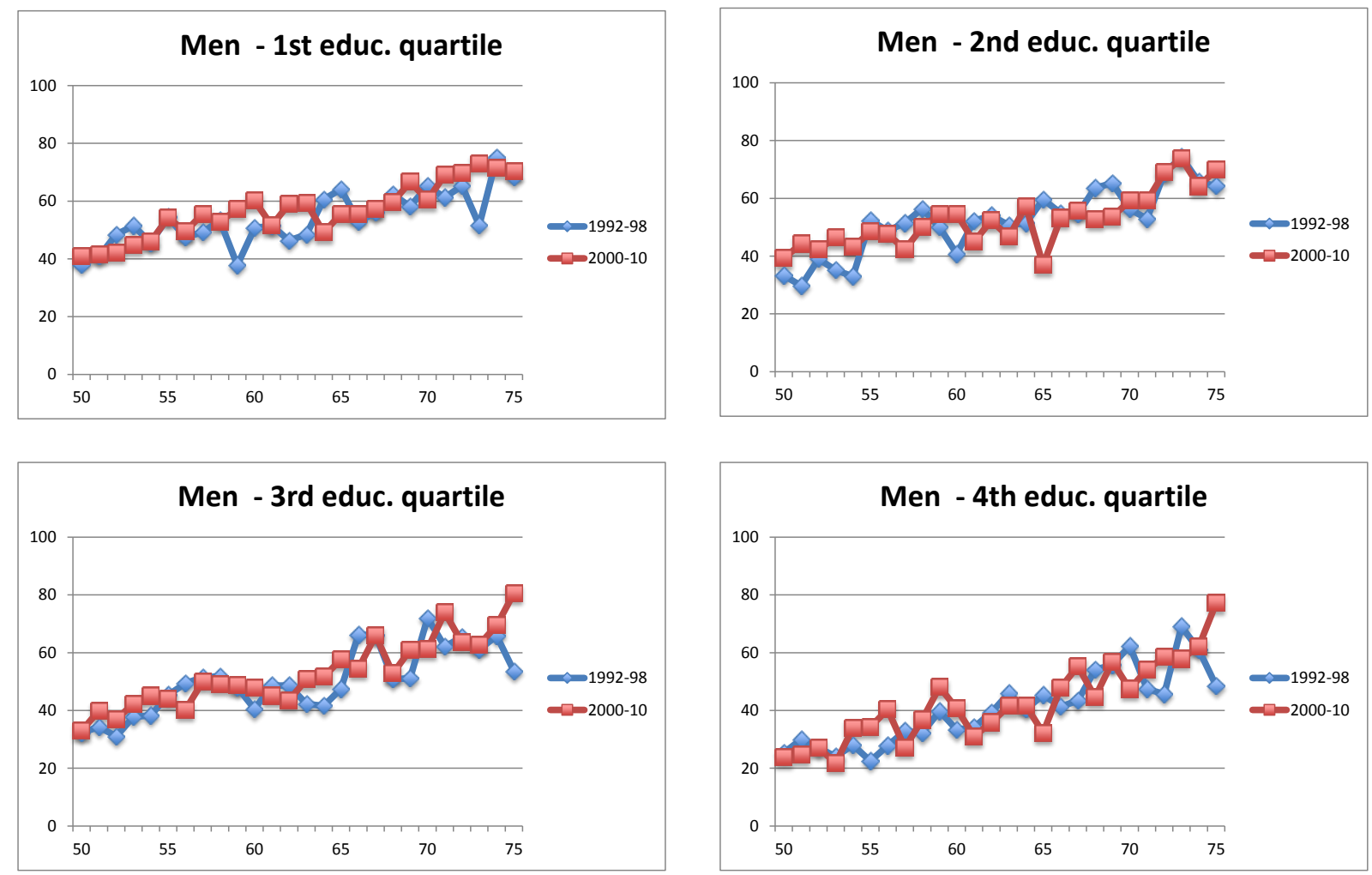
Figure 15 - Poor SAH by education quartile - Women

1992-2010
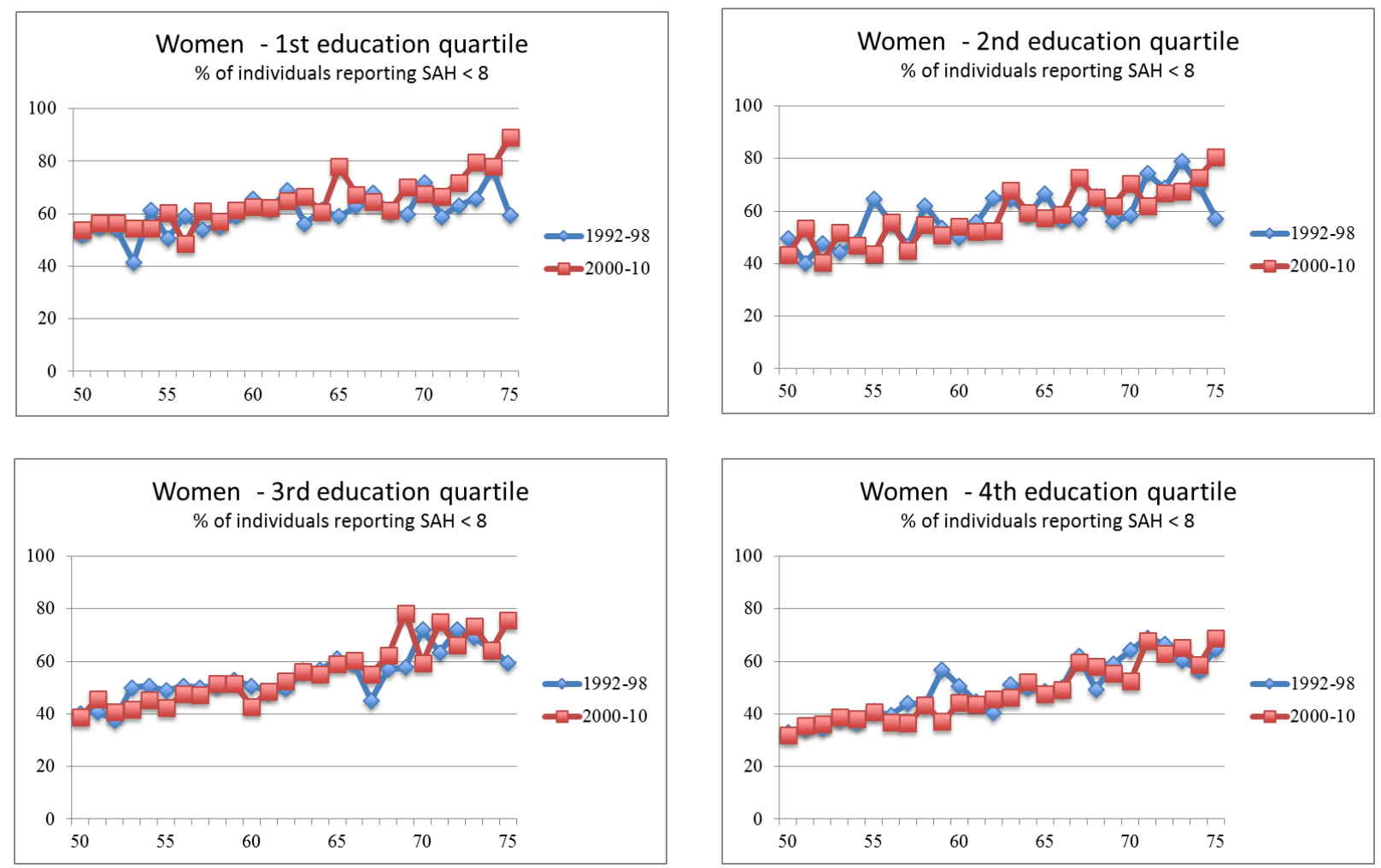

As evidenced in Figures 14 and 15 above, higher-educated men and women are on average in better health than their low-educated counterparts. This is particularly true for both men and women in the fourth quartile of the education distribution. However, we find no evidence of a substantial improvement in SAH over time except at very old ages - for men in the upper half of the education distribution and for women in the first and third quartiles. This result has to be interpreted with caution though since individuals in very bad health above 70 years old are likely to be underrepresented in the ESPS survey if they are hosted in specialized institutions since the latter are not included in the sample. If the proportion of unhealthy older people in such institutions has increased over time, the group of older individuals in the ESPS survey is increasingly selected in terms of health, which may account for the trend observed in our data at very old ages.

Overall, we do not see very different trends in health conditions over time within age and education groups. So, the lack of steady improvement in self-assessed health observed in the French data cannot be accounted for by the fact that health conditions would improve for 
some groups of individuals while worsening for others, at least when these groups are defined on the basis of education.

\section{Additional work capacity: the Milligan-Wise approach based on SAH}

We repeat the analysis carried out for employment rates and mortality using SAH. As for mortality, we do so for men only since the strong increase in female labor force participation would generate some confusion in the interpretation of the results. To reduce the noise in the data, we average the information on SAH over two years when it is available yearly, so that what is indicated as 1992 is actually computed as the average over 1992 and 1993. In addition, we linearly adjust the age profiles of self-assessed health. The corresponding employment-health profiles are presented in Figure 16.

\section{Figure 16 - Employment vs Poor SAH - Men}

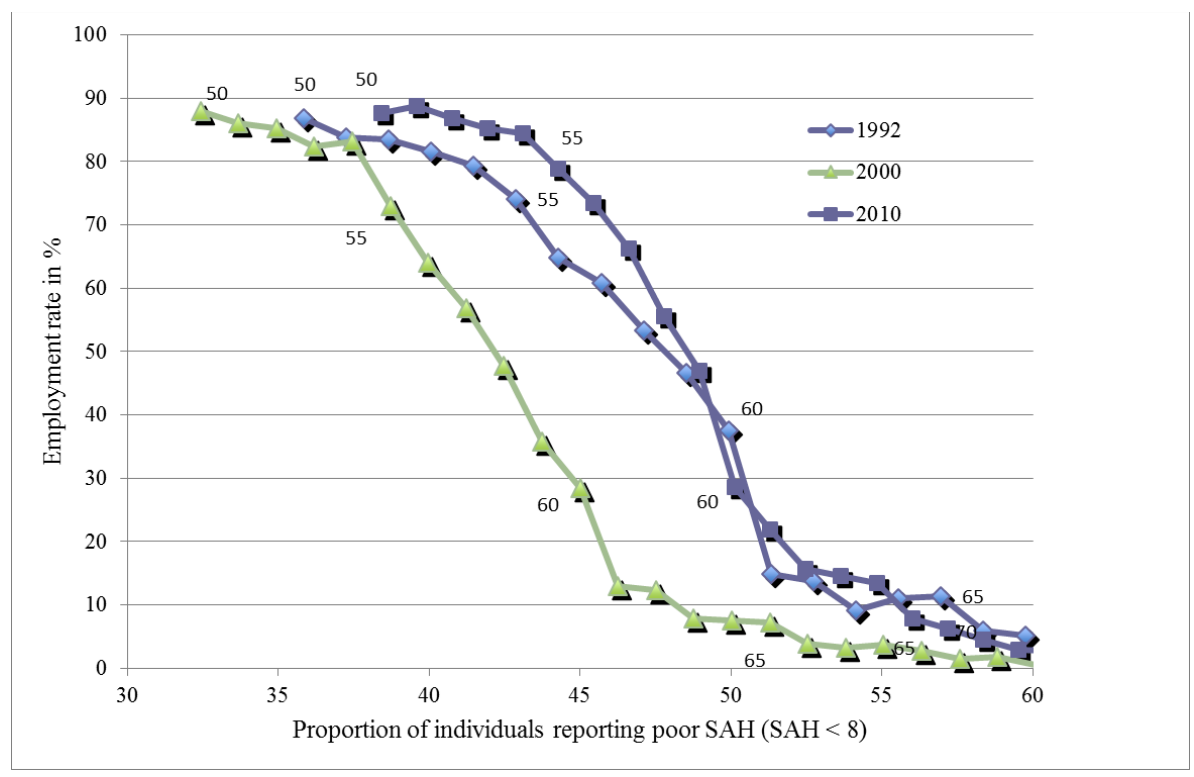

We graph employment rates as a function of the proportion of individuals reporting poor SAH for three different years: 1992, 2000 and 2010. For given shares of men in poor health, employment rates decreased substantially between 1992 and 2000, before reincreasing sharply in the 2000s. Whatever the share of men reporting poor SAH, employment rates are higher in 2010 than in 2000 and in a number of cases, they are even higher than in 1992. 
This suggests that the additional work capacity of men aged 55 to 69 as measured in 2010 is likely to be very small if not negative for a large number of years. This is what is evidenced on Figure 17 below.

\section{Figure 17 -SAH-based additional work capacity for men 55-69 in 2010 using 1992 to 2010 as reference years}

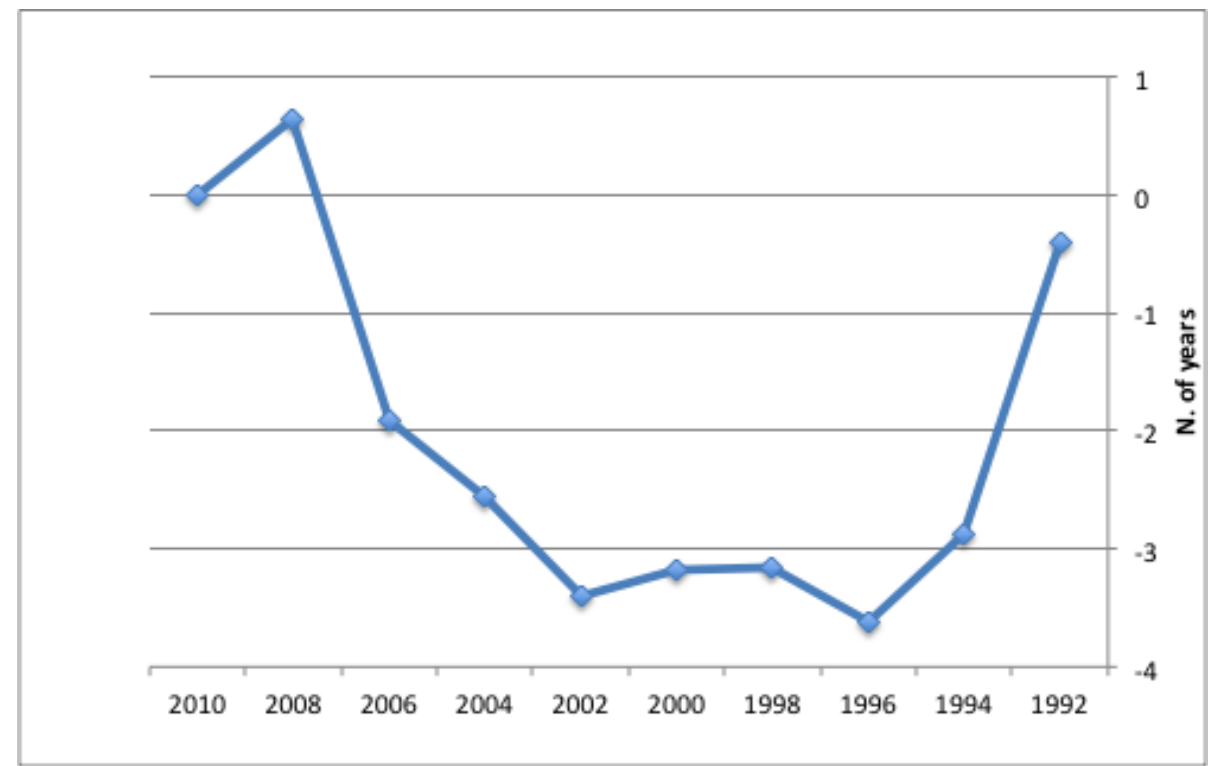

According to the reference year, the additional employment capacity as measured in 2010 varies between 0 and -3.6 years. The only reference year for which it is positive is 2008 and, even in this case, it amounts to less than 1 year. These results are due to the fact that over the 1992-2010 period, employment rates varied very little and that the proportion of men reporting poor SAH first decreased before increasing again in the second half of the period see Figure 10. For some age groups, it is even higher at the end than at the beginning of the period. Given such trends, there cannot be, by construction, any positive additional work capacity as measured in 2010 .

This result is in sharp contrast with what we obtained when using mortality as a proxy of health. As measured in 2012, the mortality-based additional work capacity varied between 0 and +3.2 years according to the choice of the reference year in the 1992-2012 range. This gap in estimates with the SAH-based additional work capacity is due to the diverging trends in mortality and SAH over the period: while death rates have steadily decreased, SAH reported by men first improved before deteriorating again. One explanation for these 
differences in trends is that mortality and SAH do not capture the same thing. Mortality is actually a very peculiar measure of health. It captures the fact that individuals are still living, rather than dead - which is, of course, positive! -, but it does not take at all into account that individuals may be living in poor health conditions. Recent work by Sieurin et al. (2011) suggests that, in France, male life expectancy at 50 increased by about 22\% between 1999 and 2008, whereas life expectancy without functional limitations increased by only $0.6 \%$ over the same period. When decomposing this trend for various types of limitations, they find that although life expectancy without physical functional limitations increased over time for men aged 50, their life expectancy without sensory and cognitive limitations actually decreased (by 3 to $8 \%$ ). If SAH reported by men partly reflects these limitations, it is no surprise that its trend might substantially differ from that of mortality.

Overall, the results presented in Sections 2 and 3 suggest that one has to be very cautious when considering our estimates of additional work capacity. Their magnitude much depends indeed on the reference year that is chosen but, more importantly, their sign reverts when considering SAH rather than mortality as the relevant measure of health because the time trends in both variables do diverge. To overcome the problems raised by comparing different time periods, the Cutler et al. method, used in the next section, relies on comparisons across age groups rather than over time.

\section{Simulating employment rates at older ages: the Cutler et al. (2013) approach}

\section{The method}

The method proposed by Cutler et al. (2013) to estimate the employment capacity consists in two steps. They first estimate individual labor force participation as a function of health for individuals in a younger age group (57-61) and then use the estimated coefficients to simulate what labor force participation would be for an older age group (62-64) if the health-participation relationship remained stable across ages. The advantage of this method is that it does not require comparing labor market outcomes and health at different points in time. The model is estimated for one age group at one period and is used to simulate the contemporaneous work capacity of another age group. The key assumption underlying the method is that the impact of health on individuals' working capacity is the same in the various age groups. 
In what follows we apply the Cutler et al. method to employment rates rather than labor force participation. We estimate employment rates separately for men and women in the 51-54 year-old group as a function of education, marital status, ${ }^{1}$ the type of job (employee, civil servant, self-employed) and an indicator of health. We then simulate employment rates for men and women and by education level separately in the 55-59, 60-64, 65-69 and 70+ age groups. Of course, the ideal methodology would require estimating separate regressions by education level. Unfortunately, we do not have enough observations in our data to do so.

\section{The data}

The data we use come from the French section of the Survey of Health, Ageing and Retirement in Europe. SHARE is a panel database containing individual information on health, socio-economic status and social and family networks for more than 85,000 individuals aged 50 and over in 19 European countries. The sample size for France is around 3,000 households per wave. The survey was carried out in 2004, 2007, 2009, 2011 and 2013. We pool all available waves except SHARELIFE (wave 3) which has data on individuals' life histories.

Our main health index is the same as in Behaghel et al. (2014). Its computation follows the methodology developed by Poterba, Venti and Wise (2010, PVW) using the American Health and Retirement Survey data. The authors assume that latent health is revealed by responses to the long list of questions asked in the survey relative to health status and changes in health status. The PVW health index is then defined as the first principal component of these selected health measures. It is a weighted average of the health indicators with weights chosen to maximize the proportion of the variance of the individual health index that can be explained by this first principal component. This methodology has been replicated on the 25 health questions of the SHARE questionnaire. Details on the selected questions and the weights are provided in Behaghel et al. (2014). The index is decomposed in percentiles with percentile 1 corresponding to the worst health status and percentile 100 to the best. Unsurprisingly, the PVW index decreases with age - see Figure 18. It is also lower for women than for men at all ages except above 93, which is consistent with widespread evidence in the literature according to which women report worse health than men do even if they have longer life expectancies - see Case and Paxson (2005).

\footnotetext{
${ }^{1}$ Race is not available in French data.
} 


\section{Figure 18 - PVW Synthetic Health Index, by age and gender Average values over 2004, 2007, 2011 and 2013}

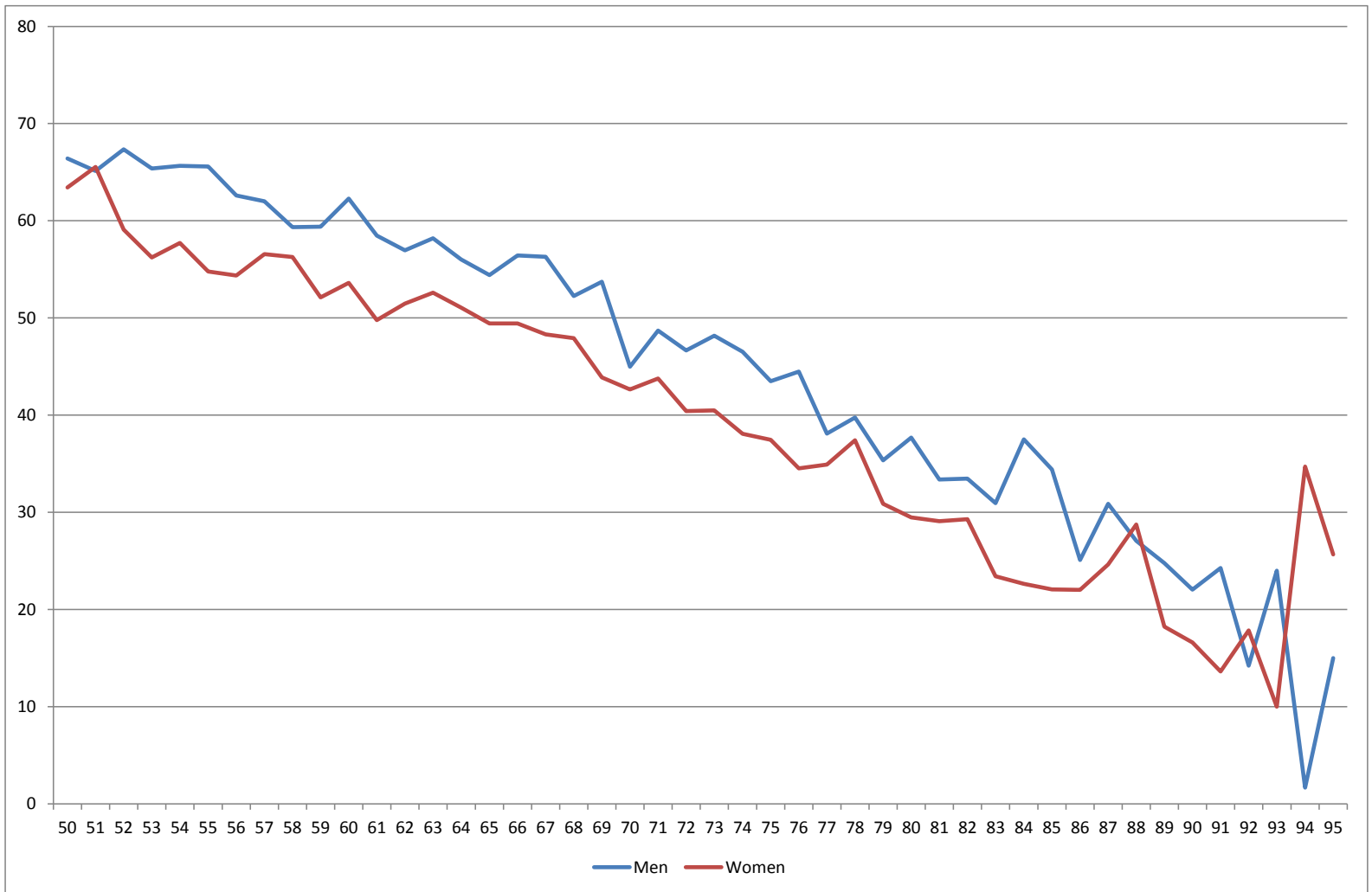

As robustness checks, we consider alternative health measures. The first set includes self-assessed health and the subset of variables contained in the PVW index which capture the lack of personal autonomy suffered by individuals. Self-assessed health is captured by a dummy variable equal to 1 if individuals report that their health is either fair or poor and 0 if they report that it is excellent, very good or good. We also include dummy variables for any difficulty walking, limitations in the activities of daily living ${ }^{2}$ and any limitation in instrumental activities of daily living. ${ }^{3}$ On the graphs, all values are averaged over the four waves of SHARE that we use. Figures AA1 and AA2 in the Appendix report age gradients for these variables.

In a third model, we include a subset of health indicators corresponding to the most severe conditions (heart problems, high blood pressure, stroke, diabetes, lung disease and cancer) as well as arthritis to the extent that it is highly incapacitating with respect to

\footnotetext{
${ }^{2}$ Limitations in the activities of daily living refer to people who need the help of others to address personal care needs, such as eating, bathing, dressing or getting around inside their home

${ }^{3}$ Limitations in instrumental activities of daily living refer to people who need the help of other persons in handling routine needs, such as everyday household chores, doing necessary business, shopping, or getting around for other purposes.
} 
employment. The age gradients for these variables are provided in Figures AA3 and AA4 for men and women, respectively.

\section{Estimating work capacity}

Results from linear regressions of employment rates on the PVW health index and our set of control variables are presented in Table 1 below.

Table 1 - Employment rates and the PVW Health Index

Men and Women aged 51-54

\begin{tabular}{|l|c|c|}
\hline \hline Dependent variable: Employment rate & Men & Women \\
\hline \hline Constant & $0.567 * * *$ & $0.553^{* * *}$ \\
PVW synthetic health index & $(0.052)$ & $(0.042)$ \\
No diploma or primary school & $0.004^{* * *}$ & $0.004 * * *$ \\
& $(0.001)$ & $(0.000)$ \\
Lower secondary education & $-0.256^{* * *}$ & $-0.109^{* * *}$ \\
& $(0.041)$ & $(0.039)$ \\
Higher secondary education & $-0.230^{* * *}$ & -0.008 \\
& $(0.060)$ & $(0.042)$ \\
High school diploma and above & -0.033 & 0.001 \\
& $(0.032)$ & $(0.029)$ \\
Employee & Ref & Ref \\
Civil servant & - & - \\
& Ref & Ref \\
Self-Employed & - & - \\
& $0.092^{* * *}$ & 0.016 \\
Married & $(0.032)$ & $(0.029)$ \\
& 0.061 & 0.056 \\
\hline \hline Observations & $(0.041)$ & $(0.044)$ \\
R-squared & 0.033 & $0.092^{* * *}$ \\
\hline \hline
\end{tabular}

Note: standard errors in parentheses. $* * * p<0.01, * * p<0.05, * p<0.1$

As expected, the PVW health index is positively correlated with employment rates for both men and women, suggesting that individuals in better health conditions have a higher probability of being in employment. Consistent with the evidence in the literature, we also find that lower educated individuals are less likely to be in employment: the effect is significant for both men and women with no diploma or only primary school, and for men 
with at most with at most lower secondary education. Other control variables are found to have a differential impact on genders: civil-servant males have a higher probability to be in employment than employees, whereas the effect is not significant for females. In contrast, in the 51-54 year-old group considered here, married women are more likely to be employed than non-married ones, which is not the case for men.

Following the Cutler et al. (2013) methodology, we use the coefficients estimated in Table 1 to simulate employment rates for men and women in older age groups. The corresponding results are shown in Table 2.

These estimates yield large additional work capacities on average. Considering individuals aged 55-59, who are the most comparable to those on whom employment rates are estimated - who are aged 51-54 - work capacity ranges between 9\% and 19\% for men. It increases with the level of education except for the most educated group - those with highschool diploma or more - whose actual employment rate is already quite high (about $80 \%$ ). This is consistent with the fact that, although low-educated workers exit the labor force before highly-educated ones, they tend to be in worse health, thus having lower predicted employment rates. As regards women of the same age, their additional work capacity is much lower since they work even more than men in that age group. For women with no diploma or only primary education, it is about $3 \%$, even slightly negative for those with lower secondary education and no more than $12 \%$ for those with higher secondary education. This suggests that in the 55-59 year-old group, there is not much room for maneuver to increase employment rates of females.

The estimated work capacities are much larger in the 60-64 year-old group for both men and women, ranging from 46 to $69 \%$ for the former and 49 to $65 \%$ for the latter. This is due to the fact that predicted employment rates are close to those of the 55-59 age group whereas actual employment rates precipitate: they go down to no more than $30 \%$ for men and $26 \%$ for women. This is no surprise given that, during most of the period we consider here (2004-2013), legal retirement age was 60 in France, thus generating a spike in exit rates from employment at this age. The results presented in this table suggest that if health were the only limitation to the employment of senior workers, both men and women could work much more than they actually do in the 60-65 age group. 
Table 2 - Work capacity by education

Men and Women aged 55 to $70+$

\begin{tabular}{|c|c|c|c|c|c|c|}
\hline & \multicolumn{6}{|c|}{ Age 55-59 } \\
\hline \multirow[t]{2}{*}{$\%$ of individuals in employment } & \multicolumn{3}{|c|}{ Men } & \multicolumn{3}{|c|}{ Women } \\
\hline & Actual & Predicted & $\begin{array}{c}\text { Estimated } \\
\text { WC }\end{array}$ & Actual & Predicted & $\begin{array}{l}\text { Estimated } \\
\text { WC }\end{array}$ \\
\hline No diploma or primary school & $49.43 \%$ & $58.93 \%$ & $9.50 \%$ & $65.99 \%$ & $69.07 \%$ & $3.08 \%$ \\
\hline Lower secondary education & $65.06 \%$ & $65.67 \%$ & $0.61 \%$ & $82.61 \%$ & $82.41 \%$ & $-0.20 \%$ \\
\hline Higher secondary education & $65.54 \%$ & $84.71 \%$ & $19.17 \%$ & $70.80 \%$ & $82.92 \%$ & $12.12 \%$ \\
\hline \multirow[t]{4}{*}{ High school diploma and above } & $79.50 \%$ & $92.53 \%$ & $13.04 \%$ & $75.70 \%$ & $85.93 \%$ & $10.23 \%$ \\
\hline & \multicolumn{6}{|c|}{ Age 60-64 } \\
\hline & \multicolumn{3}{|c|}{ Men } & \multicolumn{3}{|c|}{ Women } \\
\hline & Actual & Predicted & $\begin{array}{c}\text { Estimated } \\
\text { WC }\end{array}$ & Actual & Predicted & $\begin{array}{c}\text { Estimated } \\
\text { WC }\end{array}$ \\
\hline No diploma or primary school & $9.23 \%$ & $58.61 \%$ & $49.39 \%$ & $18.47 \%$ & $67.86 \%$ & $49.39 \%$ \\
\hline Lower secondary education & $18.18 \%$ & $65.09 \%$ & $46.91 \%$ & $17.71 \%$ & $82.87 \%$ & $65.16 \%$ \\
\hline Higher secondary education & $13.43 \%$ & $83.37 \%$ & $69.94 \%$ & $19.46 \%$ & $81.96 \%$ & $62.51 \%$ \\
\hline \multirow[t]{4}{*}{ High school diploma and above } & $30.10 \%$ & $91.19 \%$ & $61.09 \%$ & $26.30 \%$ & $84.75 \%$ & $58.45 \%$ \\
\hline & \multicolumn{6}{|c|}{ Age 65-69 } \\
\hline & \multicolumn{3}{|c|}{ Men } & \multicolumn{3}{|c|}{ Women } \\
\hline & Actual & Predicted & $\begin{array}{c}\text { Estimated } \\
\text { WC } \\
\end{array}$ & Actual & Predicted & $\begin{array}{c}\text { Estimated } \\
\text { WC }\end{array}$ \\
\hline No diploma or primary school & $2.42 \%$ & $57.47 \%$ & $55.06 \%$ & $2.05 \%$ & $67.67 \%$ & $65.62 \%$ \\
\hline Lower secondary education & $4.26 \%$ & $65.33 \%$ & $61.07 \%$ & $2.00 \%$ & $81.08 \%$ & $79.08 \%$ \\
\hline Higher secondary education & $1.39 \%$ & $82.30 \%$ & $80.92 \%$ & $0.87 \%$ & $80.60 \%$ & $79.73 \%$ \\
\hline \multirow[t]{4}{*}{ High school diploma and above } & $6.33 \%$ & $88.11 \%$ & $81.78 \%$ & $2.69 \%$ & $82.24 \%$ & $79.55 \%$ \\
\hline & \multicolumn{6}{|c|}{ Age +70} \\
\hline & \multicolumn{3}{|c|}{ Men } & \multicolumn{3}{|c|}{ Women } \\
\hline & Actual & Predicted & $\begin{array}{c}\text { Estimated } \\
\text { WC }\end{array}$ & Actual & Predicted & $\begin{array}{c}\text { Estimated } \\
\text { WC }\end{array}$ \\
\hline No diploma or primary school & $0.08 \%$ & $51.62 \%$ & $51.53 \%$ & $0.11 \%$ & $61.32 \%$ & $61.21 \%$ \\
\hline Lower secondary education & $0.74 \%$ & $54.56 \%$ & $53.83 \%$ & $0.72 \%$ & $72.50 \%$ & $71.78 \%$ \\
\hline Higher secondary education & $0.71 \%$ & $77.09 \%$ & $76.38 \%$ & $1.27 \%$ & $74.77 \%$ & $73.50 \%$ \\
\hline High school diploma and above & $0.58 \%$ & $83.07 \%$ & $82.50 \%$ & $1.07 \%$ & $77.66 \%$ & $76.59 \%$ \\
\hline
\end{tabular}

These results are robust to using alternative health measures. The first set we consider includes poor SAH, as well as any limitation in ADL or IADL and difficulty walking. As evidenced in Appendix Table A1, all these variables reduce the probability of being in employment with the effect being significant at least at the 5\% level - except for IADL for women which is significant only at the $10 \%$ level. Using this specification to simulate additional work capacity, the magnitude we get is very close to that in Table 2, although marginally larger - see Table A2 -: it ranges from 5\% to 20\% (resp. 52\% to $71 \%$ ) for men aged 55-59 (resp. 60-64) and from 5\% to $12 \%$ (resp. $72 \%$ to $87 \%$ ) for women aged 55-59 (resp. 60-64). 
When using our second set of alternative health measures based on the most severe health conditions and arthritis, the impact on employment rates gets more variable across genders - see Table A3: women are negatively affected by strokes, diabetes, arthritis and cancer, whereas men's employment rates are reduced by strokes, lung problems and arthritis only. When simulating additional work capacity on this basis, the results are very similar to those in Table 2 - see Table A4.

As evidenced in Table 2 - and confirmed in Tables A2 and A4 - the magnitude of the work capacity estimated with the Cutler et al. method gets substantially larger as age increases. It reaches $61 \%$ to $81 \%$ for men in the 65-69 age group - according to their educational level - and 65 to $79 \%$ for women before declining slightly at older ages - but still ranging between $50 \%$ and $80 \%$ for both men and women. These figures are extremely high. Taken at face value, they suggest that health is in no way a limiting factor to increasing retirement ages for both men and women in France, whatever their educational attainment. If poorer health at old ages were the only limitation to employment, employment rates could be much higher than they actually are, even for low-skilled (low-educated) workers who have often spent a large part of their career in jobs characterized by high physical strain.

\section{The issues raised by the Cutler et al. approach}

The very high values of work capacity generated by our estimates, in particular at old ages - above 70 - raise a number of issues about the method. It indeed relies on two strong assumptions.

The first one is that a given health problem has exactly the same impact on the probability of being in employment (or the work capacity) at all ages. This assumption does not necessarily hold for a couple of reasons. Despite the large number of questions in SHARE, the health indicators that we have are quite crude so that we are likely to mismeasure "true health". In particular, a given reported health symptom (say arthritis) may correspond to a better or worse "true" health status according to the intensity of the pain it generates. If this intensity tends to grow over age, the same symptom will not affect the probability of being in employment in the same way across ages. A second issue has to do with the fact that the impact of a given "true" health problem may affect productivity in a different way across ages. Older workers may, in particular, be less versatile than younger ones thereby having more difficulty to develop strategies that would allow them to circumvent a temporary physical handicap. If this is the case, the direct impact of health on the probability of being in employment is not constant across ages. More specifically, if given health conditions, as we 
measure them, have a more negative impact on older workers than on younger ones, this will generate an upward bias in our estimates of additional work capacity, with this bias increasing as the individuals we consider get older.

Of course, the simplifying assumption according to which a given health problem has exactly the same impact on the probability of being in employment (or the work capacity) at various ages is more or less acceptable according to the age gap between the group on which the estimates are run and the group for which the simulations are made. If both groups are very similar in terms of age, the assumption may be considered reasonable. If, in contrast, they are very far apart, it is unlikely to hold. This suggests that the results we obtain for individuals aged 70 and above (or even 65-69) using estimates run on individuals aged 50-54 should be interpreted with great caution.

The second assumption underlying the Cutler et al. method is that there is no reverse causality from employment to health. If, in contrast, being in employment affects health and this effect varies across ages, the estimates run on the 50-54 year-old group are biased and the simulations carried out on the older age groups yield a biased measure of the work capacity at old ages. In particular, the latter will be overestimated if work negatively affects health at old ages. The literature on the health effects of retirement suggests that this may be the case. Most papers indeed find a positive impact of retirement on physical health, whereas the results are more mixed for mental health, and even negative for cognitive outcomes - see Bassanini and Caroli (2014). This reverse causality effect is hard to take into account since it would require instrumenting health levels. Nonetheless, it cannot be ruled out and calls, here again, for caution in interpreting the results. The same remark applies to the MW methodology as well.

\section{Conclusion}

In the first part of this chapter, we have estimated additional work capacity using the standard MW method where health is proxied by mortality. According to this approach, health does not emerge as a key limiting factor to higher employment rates in the 55-69 age groups. This result comes as no surprise. As recalled in the introduction, the fact that gains in life expectancy are good news that provide a natural solution to pension problems has been regularly underlined in the French pension debate over the last two decades. It paved the way to reforms whose expected effects on retirement ages are not marginal at all. The MW method just confirms how large the window potentially opened by these gains is. Yet, this mortalitybased approach already required one first qualification, i.e. the need to incorporate socio- 
economic mortality differentials. Accounting for these differentials did not fully revert the message that had been obtained on average: there remains some additional work capacity in the MW sense of the term for all social groups. This work capacity nevertheless displays strong variations across social groups: depending upon the reference that is chosen, the gap ranges from 4 to 6 years between the two extreme cases of blue collars and managers/professionals.

When considering SAH, which is a less crude proxy of health than mortality, our estimates of additional work capacity are substantially modified. As measured in 2010, the SAH-based capacity indeed varies between 0 and -3.6 years, thus being consistently negative. The gap in estimates between mortality and SAH-based capacity is due to the diverging trends in both variables over the period. A natural explanation for this is that mortality and SAH do not capture the same thing. As a matter of fact, the mortality proxy does not take into account that individuals may still be alive although in poor health conditions.

This result is not sufficient to invalidate the idea that the financial equilibrium of pension systems can be reached by increasing retirement ages. Its significance is indeed limited by the fact that it has been established over a relatively short time period over which employment rates have been re-increasing and SAH has had a U-shaped profile without any clear long-run trend. What would be needed is an assessment of this trend over a longer time period, typically from the mid-70s onward. But, even if such an exercise should confirm a total lack of health improvement over the long run, the MW approach would still predict a current positive additional work capacity. This would indeed mirror the global decline of senior employment rates that has been observed since the 70 s, and this precisely corresponds to the kind of increases expected from pension reforms that have already been implemented. It would however mean that these reforms have come relatively close to the health barrier we try to measure here and that there is not much scope for going further than what these reforms have already planned to do.

Comparing health (or mortality) at different time periods, as required by the MW approach, raises a number of methodological problems, in particular the dependence of the results on the reference year we choose. To circumvent such problems, the last part of the chapter uses the Cutler et al. method that relies on comparisons across age groups rather than over time. Here again, the corresponding estimates yield large additional work capacities on average, with significant variation across social groups, now identified through education 
levels: low-educated individuals tend to be in worst health at older ages so that their predicted employment rates are also lower.

Overall, both the mortality-based MW approach and the CMR method predict high average levels of additional work capacity. However, the picture becomes somewhat different when disaggregating the results by social groups or education. So, our results emphasize the idea that policies that would aim at activating any estimated additional work capacity should take into account, when possible, the heterogeneity of health conditions in the population.

Moreover, as mentioned in the introduction to this chapter, additional work capacity cannot be a general indicator of how much more seniors should work. The methods used here indeed leave aside many factors that may play a role in determining the "optimal" employment rate of older workers. The fact that leisure has a positive value is the first of these factors: individual and collective choices regarding retirement ages are the result of a tradeoff between income and leisure. Workers that are fully employable and in perfectly good health may very rationally choose to allocate a large share of their "work capacity" to retirement rather than to work if they consider that they can afford to do so. Next and last, even if we restrict the question to the assessment of work capacity stricto sensu, without any message concerning how far it must be exploited, there remains the fact that health is only one of the factors that limit this work capacity. The economic literature has shown that senior workers suffer from low levels of labor demand, in particular when they are low skilled. This may be caused by health limitations if they have spent most of their careers in high-strain jobs, but it may also be the consequence of skill obsolescence (Aubert and al, 2006). Recent prospective studies have highlighted the fact that many jobs are likely to be affected by automation in the near future (Frey and Osborne, 2013). Tasks that escape automation include creative intelligence, social intelligence and perception and manipulation tasks. It is difficult to foresee the impact of age on the ability to carry out such tasks; yet it is not implausible that labor demand continues to shift towards young and middle ages, thus increasing the difficulty for older workers to stay in employment. 


\section{Reference}

Aubert, P., E. Caroli and M. Roger. 2006. "New technologies, organisation and age: firmlevel evidence", Economic Journal, 116(509), 73-93.

Bago d'Uva T., E. van Doorslaer, M. Lindeboom and O. O'Donnell. 2008. "Does Reporting Heterogeneity Bias the Measurement of Health Disparities?", Health Economics, 17(3), 351375 .

Bago d'Uva T, M. Lindeboom, O. O'Donnell and E. van Doorslaer. 2011. "Education-related Inequity in Health Care with Heterogeneous Reporting of Health", Journal of the Royal Statistical Society, Series A, 174(3), 639-664.

Bassanini A. and E. Caroli. 2014. "Is work bad for health? The role of constraint versus choice", IZA Discussion Papers ${ }^{\circ} 7891$.

Behaghel L., D. Blanchet and M. Roger. 2004. "Retirement, Early Retirement and Disability: Explaining Labor Force Participation after 55 in France" NBER Working Paper 20030.

Blanpain, N. et O. Chardon. 2011. "Les inégalités sociales face à la mort : Tables de mortalité par catégorie sociale et indices standardisés de mortalité pour quatre périodes (1976-1984, 1983-1991, 1991-1999, 2000-2008)", WP Insee, n F1108.

Calot, G. and M. Febvay. 1965. "La mortalité différentielle suivant le milieu social, période 1955-1960", Études et conjoncture, $\mathrm{n}^{\circ} 11$, Insee.

Case A. and C. Paxson. 2005. "Sex Differences in Morbidity and Mortality", Demography, 42(2), 189-214.

Cutler D., E. Meara and S. Richards-Shubik. 2013. "Health and Work Capacity of Older Adults: Estimates and Implications for Social Security Policy", mimeo, http://www.andrew.cmu.edu/user/sethrs/WorkCap_Aug2013.pdf

Conseil d'Orientation des Retraites. 2014. Évolutions et perspectives des retraites en France, Rapport annuel du COR, Juin.

Desplanques, G. 1976. La mortalité des adultes suivant le milieu social, période 1955-1971, Les Collections de l'INSEE, série D, $\mathrm{n}^{\circ} 44$.

Etilé F and C. Milcent. 2006. "Income-related reporting heterogeneity in self-assessed health: evidence from France", Health Economics, 15(9), 965-981.

Frey C.B. and M.A. Osborne. 2013. "The future of employment: how susceptible are jobs to computerization?" Working Paper Oxford University.

Lindeboom M. and E. van Doorslaer. 2004. "Cut-point shift and index shift in self-reported health", Journal of Health Economics, 23(6), 1083-1099.

Milligan K. and D. Wise. 2012. "Health and Work at Older Ages: Using Mortality to Assess the Capacity to Work across Countries", NBER Working Paper w18229.

Sieurin A., E. Cambois and J.M. Robine. 2011. "Les espérances de vie sans incapacité en France. Une tendance récente moins favorable que dans le passé", INED Working Paper $\mathrm{n}^{\circ} 170$.

Tubeuf S., F. Jusot, M. Devaux and C. Sermet. 2008. "Social heterogeneity in self-reported health status and measurement of inequalities in health", IRDES Working Paper DT12. 


\section{Appendix}

Figure AA0 - Distribution of years of education completed by cohort - All (year each cohort attained age 50)

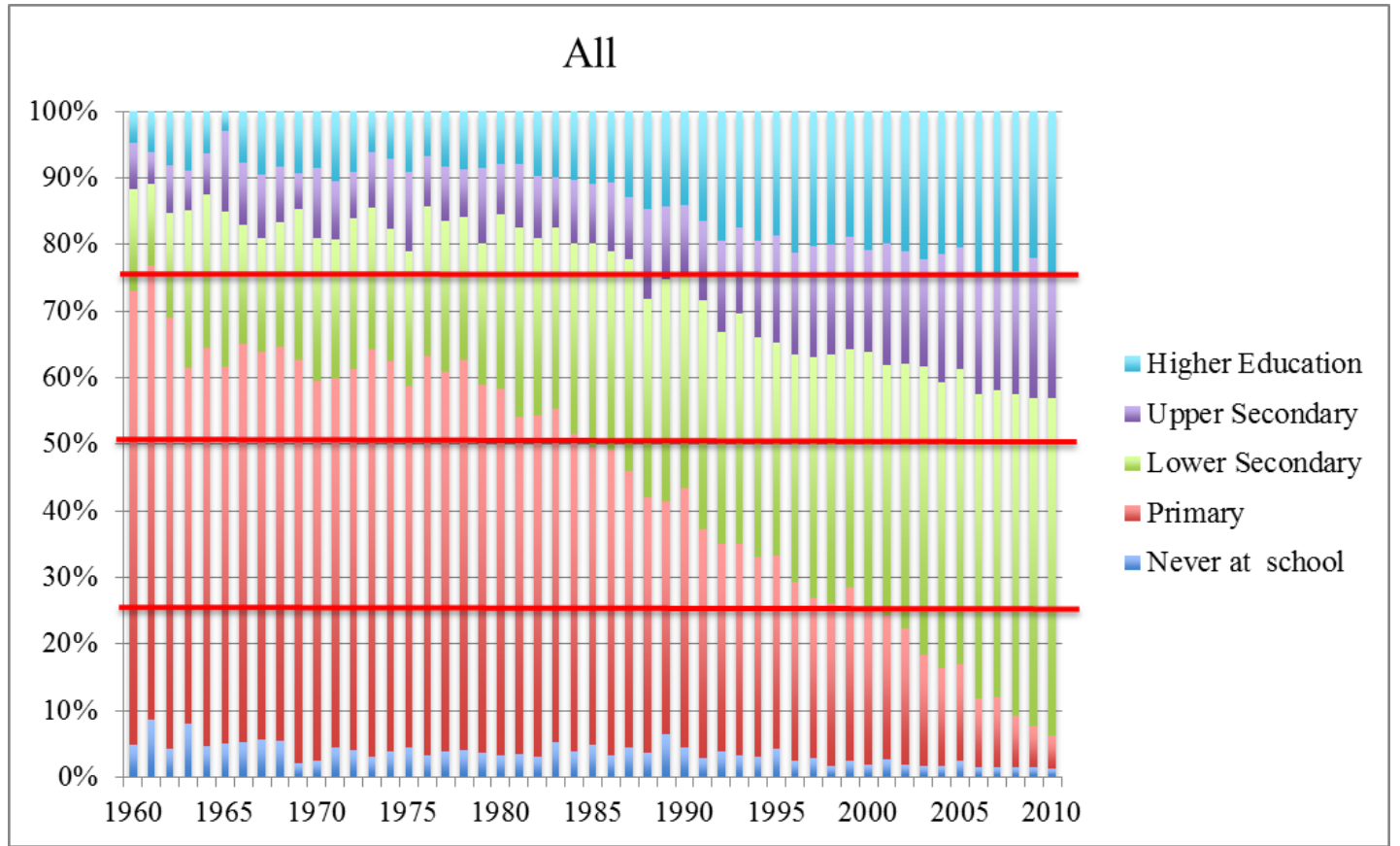

Figure AA1 - Poor SAH, Limitations in ADL and IADL, difficulty walking Men - Average values over 2004, 2007, 2011 and 2013

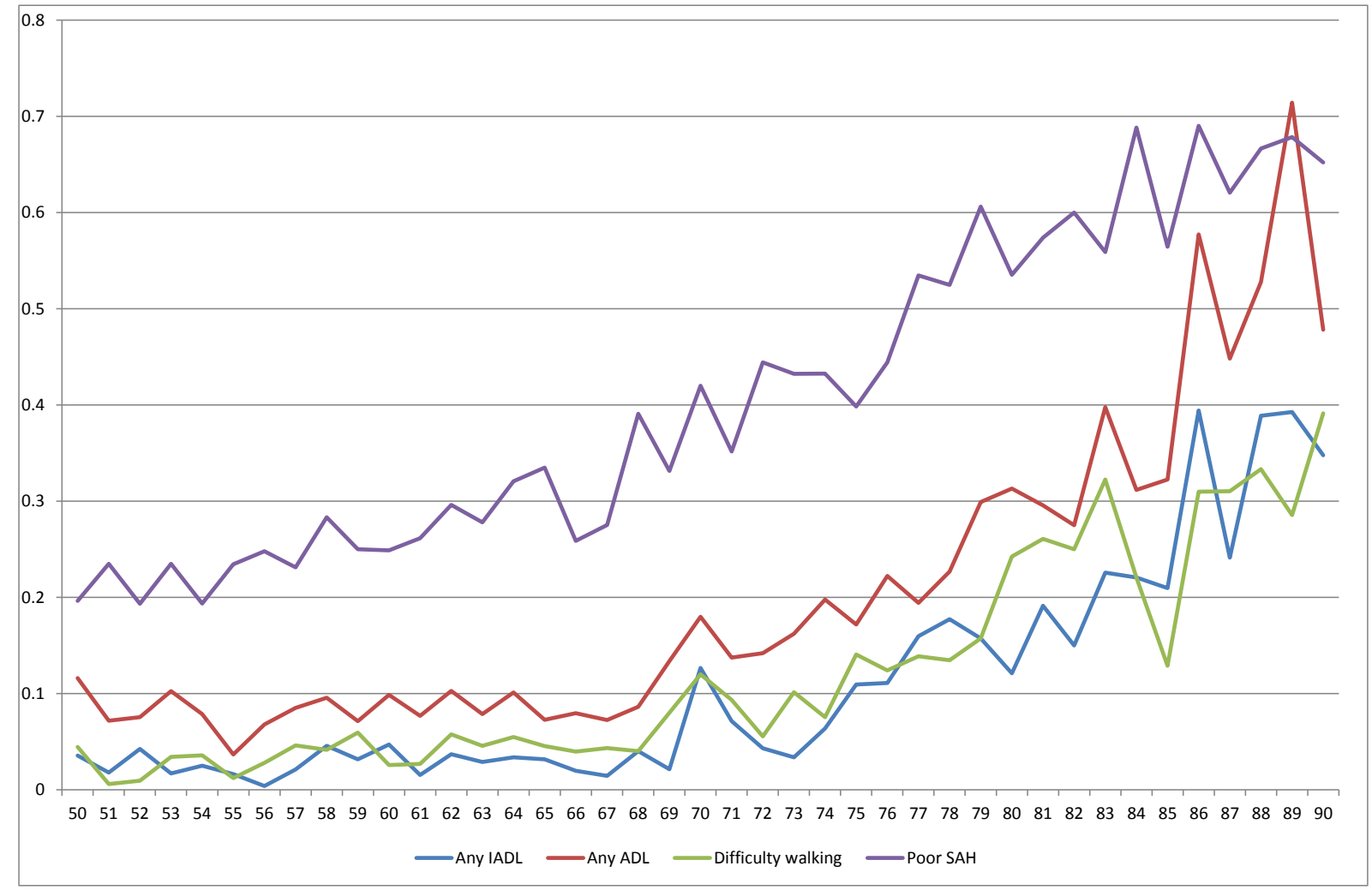


Figure AA2 - Poor SAH, Limitations in ADL and IADL, difficulty walking Women - Average values over 2004, 2007, 2011 and 2013

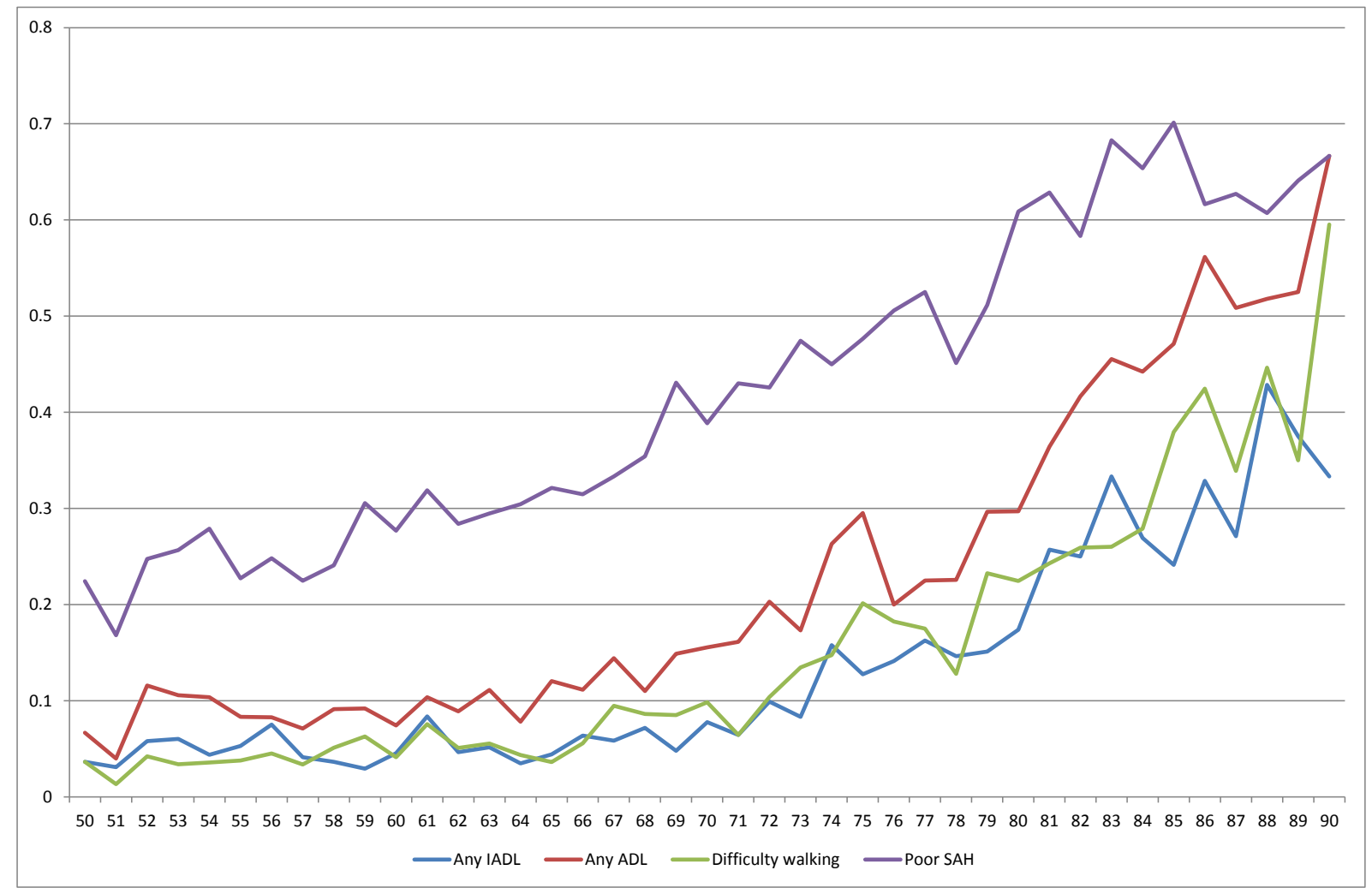


Figure AA3 - Most severe health conditions and arthritis

Men - Average values over 2004, 2007, 2011 and 2013

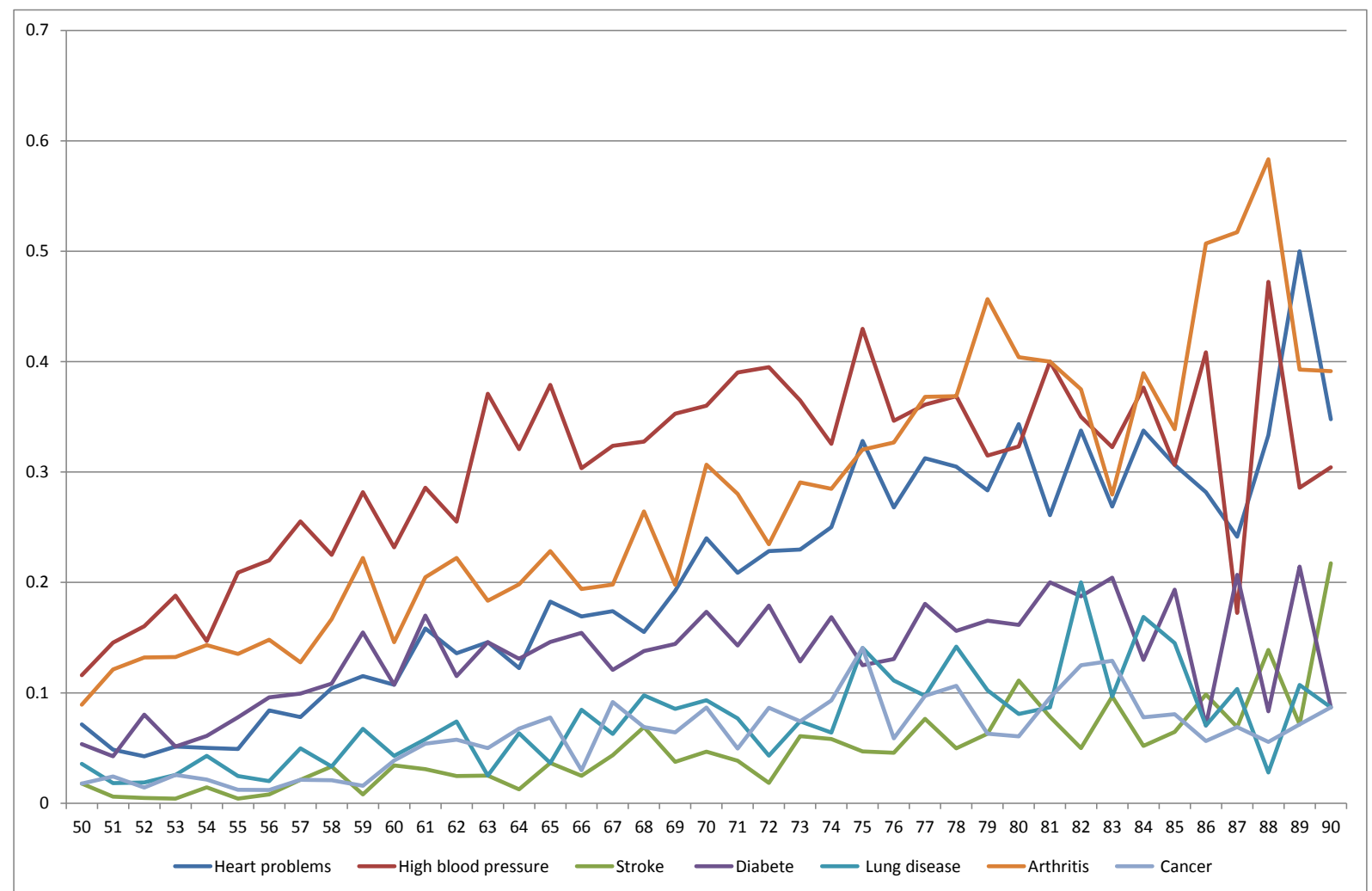


Figure AA4 - Most severe health conditions and arthritis

Women - Average values over 2004, 2007, 2011 and 2013

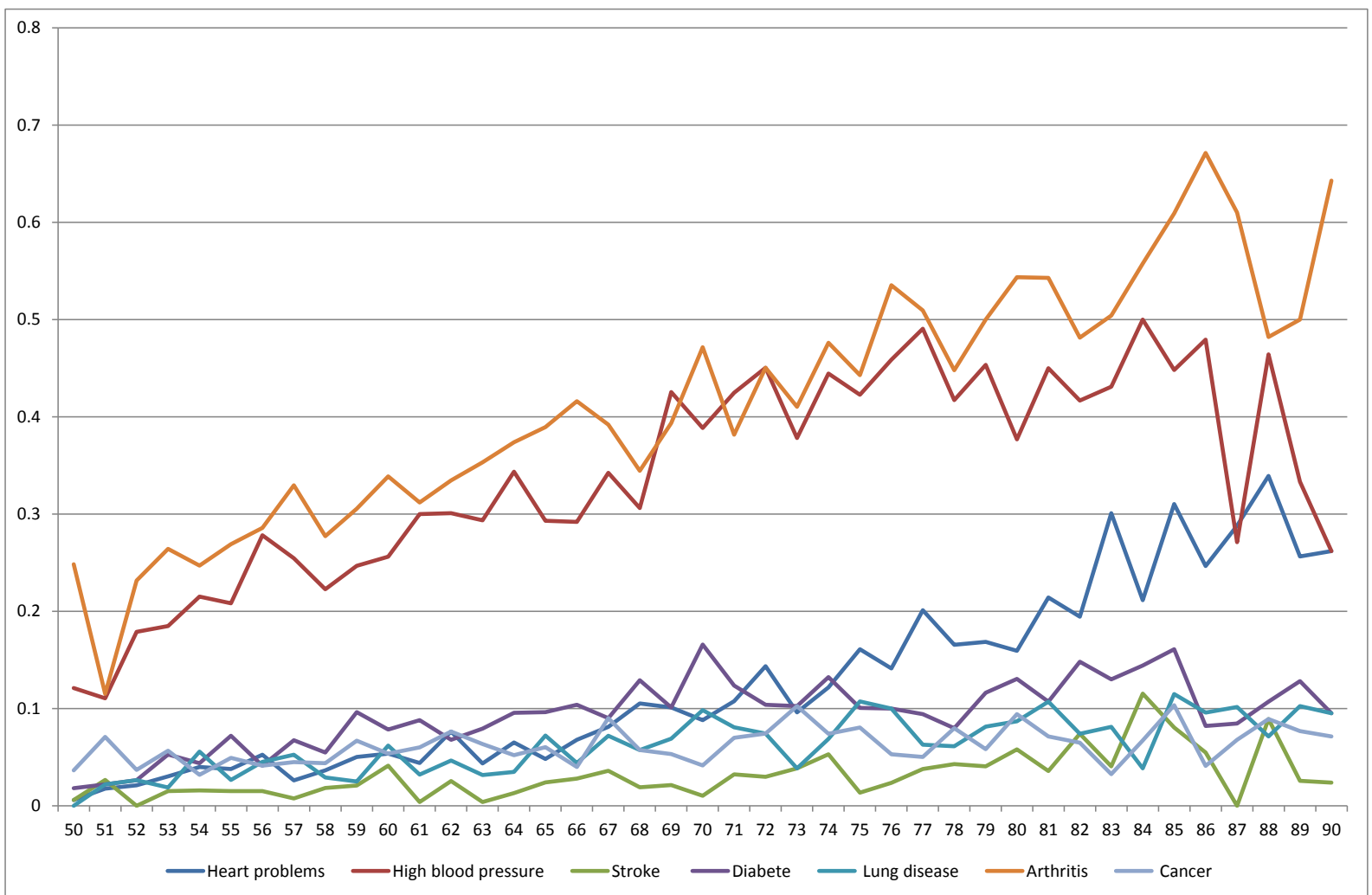


Table A1 - Employment rates and Poor SAH, ADL, IADL and difficulty walking Men and Women aged 51-54

\begin{tabular}{|c|c|c|}
\hline Dependent variable: Employment rate & Men & Women \\
\hline Constant & $\begin{array}{c}0.908 * * * \\
(0.035)\end{array}$ & $\begin{array}{c}0.851 \text { *** } \\
(0.031)\end{array}$ \\
\hline Poor SAH & $\begin{array}{c}-0.169 * * * \\
(0.034)\end{array}$ & $\begin{array}{c}-0.115^{* * * *} \\
(0.031)\end{array}$ \\
\hline Any IADL & $\begin{array}{c}-0.236^{* * *} \\
(0.079)\end{array}$ & $\begin{array}{c}-0.103^{*} \\
(0.057)\end{array}$ \\
\hline Any ADL & $\begin{array}{c}-0.163 * * * \\
(0.048)\end{array}$ & $\begin{array}{c}-0.164 * * * \\
(0.045)\end{array}$ \\
\hline Difficulty walking & $\begin{array}{c}-0.202 * * \\
(0.081)\end{array}$ & $\begin{array}{c}-0.385 * * * \\
(0.070)\end{array}$ \\
\hline No diploma or primary school & $\begin{array}{c}-0.239 * * * \\
(0.040)\end{array}$ & $\begin{array}{c}-0.086 * * \\
(0.038)\end{array}$ \\
\hline Lower secondary education & $\begin{array}{c}-0.211 * * * \\
(0.058)\end{array}$ & $\begin{array}{l}-0.017 \\
(0.040)\end{array}$ \\
\hline Higher secondary education & $\begin{array}{c}-0.033 \\
(0.030)\end{array}$ & $\begin{array}{l}-0.005 \\
(0.028)\end{array}$ \\
\hline High school diploma and above & $\begin{array}{c}\text { Ref } \\
-\end{array}$ & $\begin{array}{c}\text { Ref } \\
-\end{array}$ \\
\hline Employee & $\begin{array}{c}\text { Ref } \\
-\end{array}$ & $\begin{array}{c}\text { Ref } \\
-\end{array}$ \\
\hline Civil servant & $\begin{array}{c}0.083 * * * \\
(0.031)\end{array}$ & $\begin{array}{c}0.015 \\
(0.027)\end{array}$ \\
\hline Self-Employed & $\begin{array}{l}0.068^{*} \\
(0.039)\end{array}$ & $\begin{array}{c}0.083 * * \\
(0.042)\end{array}$ \\
\hline Married & $\begin{array}{c}0.034 \\
(0.029) \\
\end{array}$ & $\begin{array}{c}0.086 * * * \\
(0.025)\end{array}$ \\
\hline Observations & 726 & 852 \\
\hline R-squared & 0.223 & 185 \\
\hline
\end{tabular}

Note: standard errors in parentheses. $* * * p<0.01, * * p<0.05, * p<0.1$ 
Table A2 - Work capacity by education - Men and Women aged 55 to 70+ Based on estimates in Table A1

\begin{tabular}{|c|c|c|c|c|c|c|}
\hline & \multicolumn{6}{|c|}{ Age $55-59$} \\
\hline \multirow[t]{2}{*}{$\%$ of individuals in employment } & \multicolumn{3}{|c|}{ Men } & \multicolumn{3}{|c|}{ Women } \\
\hline & Actual & Predicted & $\begin{array}{l}\text { Estimated } \\
\text { WC }\end{array}$ & Actual & Predicted & $\begin{array}{c}\text { Estimated } \\
\text { WC }\end{array}$ \\
\hline No diploma or primary school & $49.43 \%$ & $60.20 \%$ & $10.77 \%$ & $65.99 \%$ & $71.90 \%$ & $5.90 \%$ \\
\hline Lower secondary education & $65.06 \%$ & $70.32 \%$ & $5.26 \%$ & $82.61 \%$ & $87.21 \%$ & $4.61 \%$ \\
\hline Higher secondary education & $65.54 \%$ & $86.39 \%$ & $20.85 \%$ & $70.80 \%$ & $83.64 \%$ & $12.84 \%$ \\
\hline \multirow[t]{4}{*}{ High school diploma and above } & $79.50 \%$ & $93.79 \%$ & $14.29 \%$ & $75.70 \%$ & $88.63 \%$ & $12.93 \%$ \\
\hline & \multicolumn{6}{|c|}{ Age $60-64$} \\
\hline & \multicolumn{3}{|c|}{ Men } & \multicolumn{3}{|c|}{ Women } \\
\hline & Actual & Predicted & $\begin{array}{l}\text { Estimated } \\
\text { WC }\end{array}$ & Actual & Predicted & $\begin{array}{c}\text { Estimated } \\
\text { WC }\end{array}$ \\
\hline No diploma or primary school & $9.23 \%$ & $61.64 \%$ & $52.41 \%$ & $18.47 \%$ & $72.11 \%$ & $53.64 \%$ \\
\hline Lower secondary education & $18.18 \%$ & $70.29 \%$ & $52.10 \%$ & $17.71 \%$ & $86.05 \%$ & $68.34 \%$ \\
\hline Higher secondary education & $13.43 \%$ & $85.41 \%$ & $71.97 \%$ & $19.46 \%$ & $83.29 \%$ & $63.84 \%$ \\
\hline \multirow[t]{4}{*}{ High school diploma and above } & $30.10 \%$ & $91.77 \%$ & $61.67 \%$ & $26.30 \%$ & $87.28 \%$ & $60.98 \%$ \\
\hline & \multicolumn{6}{|c|}{ Age 65-69 } \\
\hline & \multicolumn{3}{|c|}{ Men } & \multicolumn{3}{|c|}{ Women } \\
\hline & Actual & Predicted & $\begin{array}{l}\text { Estimated } \\
\text { WC }\end{array}$ & Actual & Predicted & $\begin{array}{c}\text { Estimated } \\
\text { WC }\end{array}$ \\
\hline No diploma or primary school & $2.42 \%$ & $61.31 \%$ & $58.89 \%$ & $2.05 \%$ & $71.49 \%$ & $69.44 \%$ \\
\hline Lower secondary education & $4.26 \%$ & $69.04 \%$ & $64.79 \%$ & $2.00 \%$ & $80.83 \%$ & $78.83 \%$ \\
\hline Higher secondary education & $1.39 \%$ & $85.03 \%$ & $83.64 \%$ & $0.87 \%$ & $82.85 \%$ & $81.98 \%$ \\
\hline \multirow[t]{4}{*}{ High school diploma and above } & $6.33 \%$ & $90.98 \%$ & $84.66 \%$ & $2.69 \%$ & $84.63 \%$ & $81.94 \%$ \\
\hline & \multicolumn{6}{|c|}{ Age +70} \\
\hline & \multicolumn{3}{|c|}{ Men } & \multicolumn{3}{|c|}{ Women } \\
\hline & Actual & Predicted & $\begin{array}{c}\text { Estimated } \\
\text { WC }\end{array}$ & Actual & Predicted & $\begin{array}{c}\text { Estimated } \\
\text { WC }\end{array}$ \\
\hline No diploma or primary school & $0.08 \%$ & $48.82 \%$ & $48.74 \%$ & $0.11 \%$ & $57.50 \%$ & $57.38 \%$ \\
\hline Lower secondary education & $0.74 \%$ & $53.44 \%$ & $52.70 \%$ & $0.72 \%$ & $71.19 \%$ & $70.48 \%$ \\
\hline Higher secondary education & $0.71 \%$ & $76.98 \%$ & $76.27 \%$ & $1.27 \%$ & $73.10 \%$ & $71.82 \%$ \\
\hline High school diploma and above & $0.58 \%$ & $84.45 \%$ & $83.87 \%$ & $1.07 \%$ & $78.76 \%$ & $77.69 \%$ \\
\hline
\end{tabular}


Table A3 - Employment rates and most serious health conditions Men and Women aged 51-54

\begin{tabular}{|c|c|c|}
\hline Dependent variable: Employment rate & Men & Women \\
\hline Constant & $\begin{array}{c}0.899 * * * \\
(0.037)\end{array}$ & $\begin{array}{c}0.849 * * * \\
(0.032)\end{array}$ \\
\hline Heart problem & $\begin{array}{l}-0.089 \\
(0.065)\end{array}$ & $\begin{array}{l}-0.087 \\
(0.083)\end{array}$ \\
\hline Blood pressure & $\begin{array}{l}-0.023 \\
(0.038)\end{array}$ & $\begin{array}{l}-0.051 \\
(0.034)\end{array}$ \\
\hline Stroke & $\begin{array}{c}-0.322^{* *} \\
(0.128)\end{array}$ & $\begin{array}{c}-0.275^{* * *} \\
(0.100)\end{array}$ \\
\hline Diabete & $\begin{array}{c}-0.014 \\
(0.057)\end{array}$ & $\begin{array}{c}-0.213 * * * \\
(0.069)\end{array}$ \\
\hline Lung problem & $\begin{array}{c}-0.233 * * * \\
(0.088)\end{array}$ & $\begin{array}{l}-0.026 \\
(0.073)\end{array}$ \\
\hline Arthritis & $\begin{array}{c}-0.088 * * \\
(0.039)\end{array}$ & $\begin{array}{c}-0.066 * * \\
(0.030)\end{array}$ \\
\hline Cancer & $\begin{array}{c}-0.152 \\
(0.098)\end{array}$ & $\begin{array}{c}-0.199 * * * \\
(0.059)\end{array}$ \\
\hline No diploma or primary school & $\begin{array}{c}-0.299 * * * \\
(0.042)\end{array}$ & $\begin{array}{c}-0.167 * * * \\
(0.039)\end{array}$ \\
\hline Lower secondary education & $\begin{array}{c}-0.268 * * * \\
(0.061)\end{array}$ & $\begin{array}{c}-0.044 \\
(0.042)\end{array}$ \\
\hline Higher secondary education & $\begin{array}{c}-0.064 * * \\
(0.032)\end{array}$ & $\begin{array}{l}-0.019 \\
(0.029)\end{array}$ \\
\hline High school diploma and above & $\begin{array}{c}\text { Ref } \\
-\end{array}$ & $\begin{array}{c}\text { Ref } \\
-\end{array}$ \\
\hline Employee & $\begin{array}{c}\text { Ref } \\
-\end{array}$ & $\begin{array}{c}\text { Ref } \\
-\end{array}$ \\
\hline Civil servant & $\begin{array}{c}0.090 * * * \\
(0.033)\end{array}$ & $\begin{array}{c}0.029 \\
(0.029)\end{array}$ \\
\hline Self-Employed & $\begin{array}{l}0.080 * \\
(0.041)\end{array}$ & $\begin{array}{c}0.065 \\
(0.045)\end{array}$ \\
\hline Married & $\begin{array}{c}0.037 \\
(0.030) \\
\end{array}$ & $\begin{array}{c}0.091 * * * \\
(0.026) \\
\end{array}$ \\
\hline Observations & 725 & 852 \\
\hline R-squared & 0.15 & 0.104 \\
\hline
\end{tabular}

Note: standard errors in parentheses. $* * * p<0.01, * * p<0.05, * p<0.1$ 
Table A4 - Work capacity by education - Men and Women aged 55 to 70+ Based on estimates in Table A3

\begin{tabular}{|c|c|c|c|c|c|c|}
\hline \multirow{3}{*}{$\%$ of individuals in employment } & \multicolumn{6}{|c|}{ Age $55-59$} \\
\hline & \multicolumn{3}{|c|}{ Men } & \multicolumn{3}{|c|}{ Women } \\
\hline & Actual & Predicted & $\begin{array}{c}\text { Estimated } \\
\text { WC }\end{array}$ & Actual & Predicted & $\begin{array}{c}\text { Estimated } \\
\text { WC }\end{array}$ \\
\hline No diploma or primary school & $49.43 \%$ & $59.11 \%$ & $9.68 \%$ & $65.99 \%$ & $67.29 \%$ & $1.30 \%$ \\
\hline Lower secondary education & $65.06 \%$ & $65.62 \%$ & $0.56 \%$ & $82.61 \%$ & $81.74 \%$ & $-0.87 \%$ \\
\hline Higher secondary education & $65.54 \%$ & $84.57 \%$ & $19.03 \%$ & $70.80 \%$ & $83.93 \%$ & $13.13 \%$ \\
\hline \multirow[t]{4}{*}{ High school diploma and above } & $79.50 \%$ & $94.35 \%$ & $14.86 \%$ & $75.70 \%$ & $87.12 \%$ & $11.42 \%$ \\
\hline & \multicolumn{6}{|c|}{ Age $60-64$} \\
\hline & \multicolumn{3}{|c|}{ Men } & \multicolumn{3}{|c|}{ Women } \\
\hline & Actual & Predicted & $\begin{array}{l}\text { Estimated } \\
\text { WC }\end{array}$ & Actual & Predicted & $\begin{array}{c}\text { Estimated } \\
\text { WC }\end{array}$ \\
\hline No diploma or primary school & $9.23 \%$ & $58.57 \%$ & $49.34 \%$ & $18.47 \%$ & $65.31 \%$ & $46.84 \%$ \\
\hline Lower secondary education & $18.18 \%$ & $64.58 \%$ & $46.39 \%$ & $17.71 \%$ & $79.39 \%$ & $61.68 \%$ \\
\hline Higher secondary education & $13.43 \%$ & $82.38 \%$ & $68.94 \%$ & $19.46 \%$ & $83.05 \%$ & $63.59 \%$ \\
\hline \multirow[t]{4}{*}{ High school diploma and above } & $30.10 \%$ & $91.13 \%$ & $61.03 \%$ & $26.30 \%$ & $85.80 \%$ & $59.50 \%$ \\
\hline & \multicolumn{6}{|c|}{ Age $65-69$} \\
\hline & \multicolumn{3}{|c|}{ Men } & \multicolumn{3}{|c|}{ Women } \\
\hline & Actual & Predicted & $\begin{array}{l}\text { Estimated } \\
\text { WC }\end{array}$ & Actual & Predicted & $\begin{array}{c}\text { Estimated } \\
\text { WC }\end{array}$ \\
\hline No diploma or primary school & $2.42 \%$ & $56.12 \%$ & $53.71 \%$ & $2.05 \%$ & $64.01 \%$ & $61.97 \%$ \\
\hline Lower secondary education & $4.26 \%$ & $63.10 \%$ & $58.84 \%$ & $2.00 \%$ & $80.10 \%$ & $78.10 \%$ \\
\hline Higher secondary education & $1.39 \%$ & $81.18 \%$ & $79.80 \%$ & $0.87 \%$ & $82.12 \%$ & $81.25 \%$ \\
\hline \multirow[t]{4}{*}{ High school diploma and above } & $6.33 \%$ & $89.16 \%$ & $82.83 \%$ & $2.69 \%$ & $84.17 \%$ & $81.48 \%$ \\
\hline & \multicolumn{6}{|c|}{ Age +70} \\
\hline & \multicolumn{3}{|c|}{ Men } & \multicolumn{3}{|c|}{ Women } \\
\hline & Actual & Predicted & $\begin{array}{l}\text { Estimated } \\
\text { WC }\end{array}$ & Actual & Predicted & $\begin{array}{c}\text { Estimated } \\
\text { WC }\end{array}$ \\
\hline No diploma or primary school & $0.08 \%$ & $53.20 \%$ & $53.12 \%$ & $0.11 \%$ & $60.98 \%$ & $60.87 \%$ \\
\hline Lower secondary education & $0.74 \%$ & $55.45 \%$ & $54.72 \%$ & $0.72 \%$ & $74.84 \%$ & $74.13 \%$ \\
\hline Higher secondary education & $0.71 \%$ & $78.12 \%$ & $77.41 \%$ & $1.27 \%$ & $77.31 \%$ & $76.04 \%$ \\
\hline High school diploma and above & $0.58 \%$ & $85.72 \%$ & $85.15 \%$ & $1.07 \%$ & $81.14 \%$ & $80.07 \%$ \\
\hline
\end{tabular}

